\title{
ECONOMIC DYNAMICS UNDER HETEROGENEOUS LEARNING: NECESSARY AND SUFFICIENT CONDITIONS FOR STABILITY
}

\section{Dmitri Kolyuzhnov}
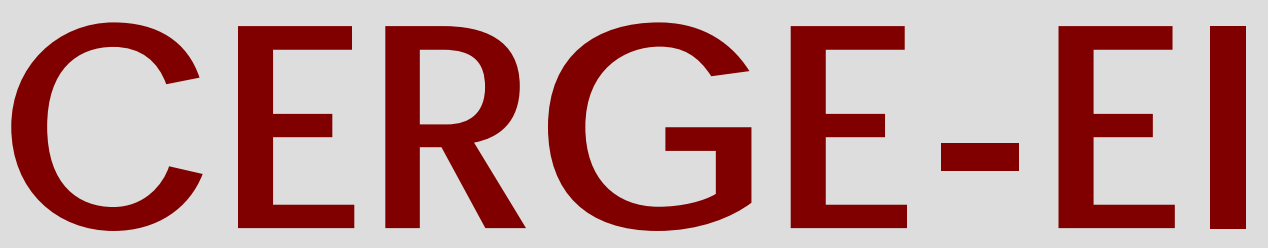

Charles University Centerfor Economic Research and Graduate Education Academy of Sciences of the Czech Republic Ec onomic s Institute 


\title{
Working Paper Series $\quad 378$ (ISSN 1211-3298)
}

\section{Economic Dynamics \\ Under Heterogeneous Learning: Necessary and Sufficient Conditions for Stability}

\author{
Dmitri Kolyuzhnov
}

CERGE-EI

Prague, December 2008 
ISBN 978-80-7343-179-2 (Univerzita Karlova. Centrum pro ekonomický výzkum a doktorské studium)

ISBN 978-80-7344-168-5 (Národohospodářský ústav AV ČR, v.v.i.) 


\title{
Economic Dynamics Under Heterogeneous Learning: Necessary and Sufficient Conditions for Stability*
}

\author{
Dmitri Kolyuzhnov ${ }^{\dagger}$
}

CERGE-EI ${ }^{\ddagger}$

Politických vězñů 7, 11121 Praha 1,

Czech Republic

\begin{abstract}
I provide sufficient conditions and necessary conditions for stability of a structurally heterogeneous economy under heterogeneous learning of agents. These conditions are written in terms of the structural heterogeneity independent of heterogeneity in learning. I have found an easily interpretable unifying condition which is sufficient for convergence of an economy under mixed RLS/SG learning with different degrees of inertia towards a rational expectations equilibrium for a broad class of economic models and a criterion for such a convergence in the univariate case. The conditions are formulated using the concept of a subeconomy and a suitably defined aggregate economy. I demonstrate and provide interpretation of the derived conditions and the criterion on univariate and multivariate examples, including two specifications of the overlapping generations model and the model of simultaneous markets with structural heterogeneity.
\end{abstract}

JEL Classification: C62, D83, E10

Keywords: adaptive learning, stability of equilibrium, heterogeneous agents

*The major part of this paper was written while the author stayed as a visiting Ph.D. student at the University of Cambridge, UK. The author expresses special thanks to his supervisor while at Cambridge, Seppo Honkapohja, for continuous support of this research and immeasurable help and advice. All errors are the author's responsibility.

The author expresses thanks to the participants of the European Economics and Finance Society (EEFS 2006) 5th Annual Conference "European Labour Markets, Trade and Financial Flows and Economic Growth" in Heraklion, Crete, Greece, May, 18-21, 2006 and CEF 2006, Limassol, Cyprus, June, 17-21, 2006 for valuable discussion.

†Dmitri.Kolyuzhnov@cerge-ei.cz.

${ }^{\ddagger} \mathrm{CERGE}-\mathrm{EI}$ is a joint workplace of the Center for Economic Research and Graduate Education, Charles University, and the Economics Institute of the Academy of Sciences of the Czech Republic. 


\begin{abstract}
Abstrakt
V této práci předkládám nutné a postačující podmínky pro stabilitu strukturálně heterogenní ekonomiky při heterogenním učení agentů. Tyto podmínky jsou určeny v pojmech strukturální heterogenity nehledě na heterogenitu učení. Našel jsem snadno interpretovatelnou sjednocující podmínku, která je postačující pro konvergenci ekonomiky při smíšeném RLS/SG učení s rozdílnými stupni setrvačnosti směrem k rovnováze racionálních očekávání pro širokou třídu ekonomických modelů a kriterií pro konvergenci $\mathrm{v}$ př́ípadě jedné proměnné. Podmínky jsou formulovány $\mathrm{s}$ použitím konceptu podekonomiky a vhodně definované agregátní ekonomiky. Předkládám interpretaci odvozených podmínek a kritérium pro př́klady s jednou a více proměnných, včetně modelu s překrytím dvou generací a modelu současných trhů se strukturální heterogenitou.
\end{abstract}




\section{Introduction}

Until some time ago, works studying models of economic dynamics assumed rational expectations of agents. However, the need to study models under bounded rationality of agents was well argumented in Sargent (1993). Later this approach was also adopted (among others) in works of Evans and Honkapohja, and a standard argument in defense of bounded rationality can be found in Evans and Honkapohja (2001), as well as in Sargent (1993).

The rational expectations (RE) approach implies that agents have a lot of knowledge about the economy (e.g., of the model structure and its parameter values). However, in empirical work, economists who assume RE equilibria in their theoretical model do not know the parameter values and must estimate them econometrically. According to the argument of Sargent (1993), it appears more natural to assume that in a given economy agents face the same limitations. It is then suggested to view agents as econometricians when forecasting the future state of the economy. Each time agents obtain new observations, they update their forecast rules. This approach introduces a specific form of bounded rationality captured by the concept of adaptive learning.

The bounded rationality approach can serve several purposes, for example, to test the validity of the RE hypothesis by checking if a given dynamic model converges over time to the rational expectations equilibrium (REE) implied by the model (under the RE hypothesis), or for equilibrium selection (in models with multiple equilibria). In both cases we have to analyze convergence of our model under adaptive learning to a REE. To do this, we need to check certain stability conditions. This introduces the area of my research: studying stability conditions in models with adaptive learning.

Following the adaptive learning literature, I consider two possible algorithms used to reflect bounded rationality: the generalized recursive least squares (RLS) and the generalized stochastic gradient (SG) algorithms. Both algorithms are examples of econometric learning. ${ }^{1}$ Each period agents update the parameter estimates

\footnotetext{
${ }^{1}$ One more type of econometric learning is Bayesian learning. See Honkapohja and Mitra (2006) for references of other forms of learning - like bounded memory rules and non-econometric learning (including computational intelligence algorithms).
} 
in the following way: the updated parameter estimate equals the previous estimate plus a linear function of the most recent forecast error multiplied by the gain parameter, capturing how important is the forecast error to the agent. The description of both algorithms can be found, for example, in Evans and Honkapohja (2001); Giannitsarou (2003); Evans, Honkapohja and Williams (2005); and Honkapohja and Mitra (2006).

The difference between the two algorithms is that the RLS algorithm ${ }^{2}$ has two updating equations: one for updating the parameters entering the forecast functions, the other - for updating the estimates of the second moments matrix of these parameters. The SG algorithm assumes this matrix fixed (reflecting modeling of "less sophisticated" agents).

The first papers taking the bounded rationality approach of Sargent (1993) considered an economy of a representative agent (assuming that all agents follow the same learning algorithm, be it RLS or SG). Later, some works began to introduce heterogeneity in the updating procedure. The idea was to check whether the representative agent hypothesis (implied by homogenous learning) in learning influences stability results. It has been demonstrated that, in general, stability under homogeneous learning does not imply stability under heterogeneous learning. Examples of such works are Giannitsarou (2003), who assumed agents homogeneous in all respects but the way they learn, and Honkapohja and Mitra (2006), who consider a general setup assuming both structural heterogeneity and heterogeneous learning. Both papers study stability conditions of the economy. Honkapohja and Mitra (2006) derive a general stability criterion, in which stability is defined both in terms of the model structure and learning characteristics.

The difference in learning characteristics across agents means heterogeneity in learning. Among these learning characteristics are initial perceptions meaning that agents may have different perceptions about the economy reflected in different initial values in their learning algorithms; the type of the updating algorithm: RLS or SG (reflecting "sophisticated" and "less sophisticated" agents, respectively); and parameters of the updating algorithm (degree of inertia) — relative weights agents

\footnotetext{
${ }^{2}$ The RLS algorithm (non-generalized) can be obtained from OLS estimation of parameters by rewriting it in the recursive form. The generalized RLS is derived from RLS by substituting the gain sequence $1 / t$ used in updating the regression coefficients with any decreasing gain sequence.
} 
put on the most recent forecast error, while updating the parameter estimates in their forecast functions (it can be called the speed of updating, reflecting how agents differ in their reaction to innovation).

A combination of all differences in the learning characteristics described above can be expressed by the type of learning when one part of agents uses the RLS algorithm and the other part uses the SG algorithm, and all of them have different degrees of inertia as well as different initial perceptions. Such type of learning algorithm is called mixed RLS/SG learning with (possibly) different degrees of inertia.

In my paper I solve the following open question posed by Honkapohja and Mitra (2006) — to find conditions for stability of a structurally heterogeneous economy under mixed RLS/SG learning with (possibly) different degrees of inertia in terms of structural heterogeneity only, independent of heterogeneity in learning.

Though Honkapohja and Mitra (2006) have formulated a general criterion for such stability and have been able to solve for sufficient conditions for the case of a univariate model (model with one endogenous variable), they did not derive the conditions (necessary, and/or sufficient) in terms of the model structure only, independent of learning characteristics, for the general (multivariate) case with an arbitrary number of agent types and any degree of inertia.

As, in essence, the criterion (in its sufficiency part) for stability of a structurally heterogeneous economy under mixed RLS/SG learning by Honkapohja and Mitra (2006) implies looking for sufficient conditions for $D$-stability of a particular stability Jacobian matrix corresponding to the model, where, according to Johnson (1974, p. 54 ), "the $D$-stables are just those matrices which remain stable under any relative reweighting of the rows or columns," I use different sets of sufficient conditions for $D$ stability of this Jacobian matrix and simplify them using a particular structure of the model, and try to provide the derived conditions with some economic interpretation.

Specifically, in this paper I conduct a systematic analysis of this problem. First, I analyze what has been done so far in mathematics on deriving sufficient conditions for stability of a matrix in the most general setup of a matrix differential equation: $\dot{x}=A x+b$, where $A$ has the form $D \Omega$, with $D$ being a positive diagonal matrix. It has turned out that the most general results can be grouped according to the perspective from which the problem was approached. 
One group of results is based on the Lyapunov theorem ${ }^{3}$ and its application to $D$-stability by the theorem of Arrow and McManus; ${ }^{4}$ another group is based on the negative diagonal dominance condition which is sufficient for $D$-stability (McKenzie theorem $^{5}$ ); a third set of results can be derived from the characteristic equation analysis, using Routh-Hurwitz necessary and sufficient conditions ${ }^{6}$ for negativity of all eigenvalues of the polynomial of order $n$; and the last set of sufficient results can be derived using an alternative definition of $D$-stability ${ }^{7}$ that allows to bypass the Routh-Hurwitz conditions.

Among the approaches mentioned above, the ones that are based on the negative diagonal dominance, the characteristic equation analysis, and the alternative definition (criterion) of $D$-stability turn out to be fruitful, each to a different extent. (The condition based on the Lyapunov theorem looks very theoretical and economically intractable here.) Using the negative diagonal dominance and the alternative definition of $D$-stability, I have derived the "aggregate economy stability" and the "same sign" sufficient conditions. As for the characteristic equation analysis, I have been able to derive a block of necessary conditions using the negativity of eigenvalues requirement, bypassing the Routh-Hurwitz conditions since they are quite complicated and do not have economic interpretation.

I have studied each group of results in application to the particular setup of models I am working with in order to make the procedure of testing for stability more tractable and at the same time to attach some economic interpretation to this very procedure. The conditions derived are then adapted by me to more simple cases of the general framework considered, namely, univariate economy and structurally homogeneous economy case.

Among the different sufficient conditions and necessary conditions that I have derived, I would like to highlight an easily interpretable unifying condition which is sufficient for convergence of a structurally heterogeneous economy under mixed RLS/SG learning with different degrees of inertia towards a rational expectations

\footnotetext{
${ }^{3}$ See Theorem A.2 in Appendix A.2.

${ }^{4}$ See Theorem A.3 in Appendix A.2.

${ }^{5}$ See Theorem A.4 in Appendix A.3.

${ }^{6}$ See Theorem A.5 in Appendix A.4.

${ }^{7}$ See Theorem A.6 in Appendix A.5.
} 
equilibrium for a broad class of economic models and a criterion for such a convergence in the univariate case. These conditions are formulated using the concept of a subeconomy and a suitably defined aggregate economy.

The rest of the paper is structured as follows. In the next section I present the environment I am working with: a structurally heterogeneous economy under mixed RLS/SG learning of agents and introduce and explain the concept of $\delta$-stability used to explain the stability of a structurally heterogeneous economy under mixed RLS/SG learning for any (possibly different) degrees of inertia of agents. Section 3 is devoted to sufficient conditions for such a stability, among which are the "aggregate economy" and the "same sign" conditions. In Section 4, I present the necessary conditions for $\delta$-stability ${ }^{8}$ that are based on the characteristic equation approach. In Section 5, I demonstrate and provide an interpretation of the derived conditions and the criterion on univariate and multivariate examples, including two specifications of the overlapping generations model and the model of simultaneous markets with structural heterogeneity. Section 6 concludes the paper.

\section{The Model and Concept of $\delta$-stability}

Deriving conditions for stability of a structurally heterogeneous economy under mixed RLS/SG learning for any (possibly different) degrees of inertia of agents, I naturally employ the general framework and notation from Honkapohja and Mitra (2006), who were the first to formulate a general criterion for stability of a structurally heterogeneous economy under mixed RLS/SG heterogeneous learning. Structural heterogeneity here means that expectations and learning rules of different agents are different, as well as may be different their fundamental characteristics, such as preferences, endowments, and technology (as opposed to structural homogeneity, which corresponds to the assumption of a representative agent).

"Mixed RLS/SG learning" refers to persistently heterogeneous learning, defined by Honkapohja and Mitra (2006) as the one arising when different agents use different types of learning algorithms. In the setup of Honkapohja and Mitra (2006) these are RLS and SG algorithms. ${ }^{9}$

\footnotetext{
${ }^{8}$ The formal definition of this concept is given in the corresponding part of the paper.

${ }^{9}$ More on this (as well as some useful reference for a more detailed study of the terms) can
} 
The class of linear structurally heterogeneous models with $S$ types of agents with different forecasts is presented by

$$
\begin{aligned}
y_{t} & =\alpha+\sum_{h=1}^{S} A_{i} \hat{E}_{t}^{h} y_{t+1}+B w_{t}, \\
w_{t} & =F w_{t-1}+v_{t}
\end{aligned}
$$

where $y_{t}$ is an $n \times 1$ vector of endogenous variables, $w_{t}$ is a $k \times 1$ vector of exogenous variables, $v_{t}$ is a vector of white noise shocks, $\hat{E}_{t}^{h} y_{t+1}$ are (in general, non-rational) expectations of the vector of endogenous variables by agent $h$. It is further assumed that $F(k \times k$ matrix $)$ is such that $w_{t}$ follows stationary $\operatorname{VAR}(1)$ process with $M_{w}=$ $\lim _{t \rightarrow \infty} w_{t} w_{t}^{\prime}$ being a positive definite matrix.

The vector form presented above is a reduced form of the model describing the whole economy, i.e., it is an equation corresponding to the intertemporal equilibrium of the dynamic model. In this model expectations of different agent types influence the current values of endogenous variables.

I also stress the diagonal structure of matrices which I analyze, namely

$$
F=\operatorname{diag}\left(\rho_{1}, \ldots, \rho_{k}\right), M_{w}=\lim _{t \rightarrow \infty} w_{t} w_{t}^{\prime}=\operatorname{diag}\left(\frac{\sigma_{1}^{2}}{1-\rho_{1}^{2}}, \ldots, \frac{\sigma_{k}^{2}}{1-\rho_{k}^{2}}\right) .
$$

Structural heterogeneity in the setup of Honkapohja and Mitra (2006) is expressed through matrices $A_{h}$, which are assumed to incorporate the mass $\zeta_{h}$ of each agent type. That is, $A_{h}=\zeta_{h} \cdot \hat{A}_{h}$, where $\hat{A}_{h}$ is defined as describing how agents of type $h$ respond to their forecasts. So these are the structural parameters characterizing a given economy. Those may be basic characteristics of agents, like those describing their preferences, endowments, and technology. Structural heterogeneity means that all $\hat{A}_{h}$ 's are different for different types of agents. When $\hat{A}_{h}=A$ for all $h$ and $\sum \zeta_{h}=1$, the economy is structurally homogenous.

In forming their expectations about the next period endogenous variables, agents are assumed to believe that the economic system develops according to the following model, which is called agents' perceived law of motion (PLM).

$$
y_{t}=a_{h, t}+b_{h, t} w_{t}
$$

be found in Honkapohja and Mitra (2006). In order not to repeat Honkapohja and Mitra (2006), I just briefly present the general setup and the general criterion of stability results. For the full presentation of the RLS/SG learning and the setup, please see Honkapohja and Mitra (2006). 
Mixed learning of agents is introduced as follows. Part of the agents, $h=\overline{1, S_{0}}$, are assumed to use the RLS learning algorithm, while others, $h=\overline{S_{0}+1, S}$, are assumed to use the SG learning algorithm. Moreover, all of them are assumed to use possibly different degrees of responsiveness to the updating function. These degrees of responsiveness are presented by different degrees of inertia $\delta_{h}>0$, which, in formulation of Giannitsarou (2003), are constant coefficients before the deterministic decreasing gain sequence in the learning algorithm, which is common for all agents. ${ }^{10}$

After denoting $z_{t}=\left(1, w_{t}\right)$ and $\Phi_{h, t}=\left(a_{h, t}, b_{h, t}\right)$, the formal presentation of the learning algorithms in this model can be written as follows.

RLS: for $h=\overline{1, S_{0}}$

$$
\begin{aligned}
& \Phi_{h, t+1}=\Phi_{h, t}+\alpha_{h, t+1} R_{h, t}^{-1} z_{t}\left(y_{t}-\Phi_{h, t}^{\prime} z_{t}\right)^{\prime} \\
& R_{h, t+1}=R_{h, t}+\alpha_{h, t+1}\left(z_{t-1} z_{t-1}^{\prime}-R_{h, t}\right)
\end{aligned}
$$

SG: for $h=\overline{S_{0}+1, S}$

$$
\Phi_{h, t+1}=\Phi_{h, t}+\alpha_{h, t+1} z_{t}\left(y_{t}-\Phi_{h, t}^{\prime} z_{t}\right)^{\prime}
$$

Honkapohja and Mitra (2006) show that stability of the REE, $\Phi_{t}$, in this model is determined by the stability of the ODE:

$$
\begin{aligned}
\frac{d \Phi_{h}}{d \tau} & =\delta_{h}\left(T\left(\Phi^{\prime}\right)^{\prime}-\Phi_{h}\right), h=\overline{1, S_{0}} \\
\frac{d \Phi_{h}}{d \tau} & =\delta_{h} M_{z}\left(T\left(\Phi^{\prime}\right)^{\prime}-\Phi_{h}\right), h=\overline{S_{0}+1, S}
\end{aligned}
$$

where $M_{z}=\lim _{t \rightarrow \infty} E z_{t} z_{t}^{\prime}=\left(\begin{array}{cc}1 & 0 \\ 0 & M_{w}\end{array}\right)$ and $T\left(\Phi^{\prime}\right)$ is a mapping of the PLM parameters into the parameters of the actual law of motion (ALM)

$$
y_{t}=\left[\alpha+\sum_{h=1}^{S} A_{h} a_{h, t},\left(\sum_{h=1}^{S} A_{h} b_{h, t}\right) F+B\right]\left[\begin{array}{c}
1 \\
w_{t}
\end{array}\right]=T\left(\Phi^{\prime}\right) z_{t}
$$

which is obtained when one plugs the forecast functions based on the agents' PLMs (4)

$$
\hat{E}_{t}^{h} y_{t+1}=a_{h, t}+b_{h, t} F w_{t}
$$

\footnotetext{
${ }^{10}$ Honkapohja and Mitra (2006) use a more general formulation of degrees of inertia as constant limits in time of the expected ratios of agents' random gain sequences and the common deterministic decreasing gain sequence satisfying certain regularity conditions.
} 
into the reduced form of the model (1) and (2). So, ${ }^{11}$

$$
T\left(a_{h, t}, b_{h, t}\right)=\left(\alpha+\sum_{h=1}^{S} A_{h} a_{h, t},\left(\sum_{h=1}^{S} A_{h} b_{h, t}\right) F+B\right) .
$$

The conditions for stability of this ODE give the general criterion of stability for this class of models presented in Proposition 5 in Honkapohja and Mitra (2006), introduced (without proof) here for the reader's convenience.

Criterion 1 (Proposition 5 in Honkapohja and Mitra (2006)) In the economy (1) and (2), mixed RLS/SG learning converges globally (almost surely) to the minimal state variable $(M S V)^{12}$ solution if and only if matrices $D_{1} \Omega$ and $D_{w} \Omega_{F}$ have eigenvalues with negative real parts, where

$$
\begin{aligned}
& D_{1}=\left(\begin{array}{ccc}
\delta_{1} I_{n} & \cdots & 0 \\
\vdots & \ddots & \vdots \\
0 & \cdots & \delta_{S} I_{n}
\end{array}\right), \Omega=\left(\begin{array}{ccc}
A_{1}-I_{n} & \cdots & A_{S} \\
\vdots & \ddots & \vdots \\
A_{1} & \cdots & A_{S}-I_{n}
\end{array}\right) \\
& D_{w}=\left(\begin{array}{ccc}
D_{w 1} & \cdots & 0 \\
\vdots & \ddots & \vdots \\
0 & \cdots & D_{w S}
\end{array}\right), \begin{array}{c}
D_{w h}=\delta_{h} I_{n k}, h=\overline{1, S_{0}} \\
D_{w h}=\delta_{h}\left(M_{w} \otimes I_{n}\right), h=\overline{S_{0}+1, S}
\end{array} \\
& \Omega_{F}=\left(\begin{array}{ccc}
F^{\prime} \otimes A_{1}-I_{n k} & \cdots & F^{\prime} \otimes A_{S} \\
\vdots & \ddots & \vdots \\
F^{\prime} \otimes A_{1} & \cdots & F^{\prime} \otimes A_{S}-I_{n k}
\end{array}\right),
\end{aligned}
$$

with $\otimes$ denoting the Kronecker product.

In the "diagonal" environment I consider, the problem of finding conditions for stability of both $D_{1} \Omega$ and $D_{w} \Omega_{F}$ under any (possibly different) degrees of inertia of agents, $\delta>0$, is simplified to finding stability conditions of $D_{1} \Omega$ and $D_{1} \Omega_{\rho_{l}}$, where $\Omega_{\rho_{l}}$ is obtained from $\Omega$ by substituting all $A_{h}$ with $\rho_{l} A_{h}$, where $\left|\rho_{l}\right|<1$ as $w_{t}$ follows stationary $\operatorname{VAR}(1)$ process by the setup of the model (see Appendix A.6 for a more detailed proof of Proposition 2 below).

$$
\Omega_{\rho_{l}}=\left(\begin{array}{ccc}
\rho_{l} A_{1}-I_{n} & \cdots & \rho_{l} A_{S} \\
\vdots & \ddots & \vdots \\
\rho_{l} A_{1} & \cdots & \rho_{l} A_{S}-I_{n}
\end{array}\right), \forall l=0, \ldots, k,\left(\rho_{0}=1\right) .
$$

\footnotetext{
${ }^{11}$ For details, please see Honkapohja and Mitra Honkapohja and Mitra (2006).

${ }^{12}$ As it is mentioned in ch. 8 of Evans and Honkapohja (2001), the concept of the MSV solution was introduced by McCallum (1983) for linear rational expectations models. As is defined in Evans and Honkapohja (2001), this is the solution that depends linearly on a set of variables (in our case it is the vector of exogenous variables and the intercept); this solution is such that there is no other solution that depends linearly on a smaller set of variables.
} 
Proposition 2 (The criterion for stability of a structurally heterogeneous economy under mixed RLS/SG learning for the diagonal environment case under any (possibly different) degrees of inertia of agents, $\delta>0)$. In the structurally heterogeneous economy (1), (2) and (3), mixed RLS/SG learning (5), (6) and (9) converges globally (almost surely) to an MSV REE solution for any (possibly different) degrees of inertia of agents, $\delta>0$, if and only if matrices $D_{1} \Omega_{\rho l}$ are stable for any $\delta>0$, where $D_{1}$ and $\Omega_{\rho_{l}}$ are defined in (11) and (12), respectively.

Proof. See Appendix A.6.

I also use the special blocked - diagonal structure of matrix $D_{1}$ which is the feature of the dynamic environment in this class of models. In a sense these positive diagonal $D$-matrices now may be called positive blocked-diagonal $\delta$-matrices. It allows me to formulate the concept of $\delta$-stability by analogy to the terminology of the concept of $D$-stability, studied for example in Johnson (1974).

Definition 1 Given n, the number of endogenous variables, and $S$, the number of agent types, $\boldsymbol{\delta}$-stability is defined as stability of the structurally heterogeneous economy (1) and (2) under mixed $R L S / S G$ learning (5), (6) and (9) under any (possibly different) degrees of inertia of agents, $\delta>0$.

$\delta$-stability, thus formulated, has the same meaning in models with heterogeneous learning described above as has the $E$-stability condition in models with homogeneous RLS learning. The E-stability condition is a condition for asymptotic stability of an REE under homogeneous RLS learning. The REE of the model is stable if it is locally asymptotically stable under the following ODE:

$$
\frac{d \theta}{d \tau}=T(\theta)-\theta
$$

where $\theta$ are the estimated parameters from agents PLMs, the $T$-map is defined in (10), and $\tau$ is a "notional" ("artificial") time. The fixed point of this ODE is the REE of the model. 


\section{Sufficient Conditions for $\delta$-stability}

\subsection{Aggregate Economy Conditions}

Following the description of the approaches to stability in the introduction, I now separately consider each of them. First, I follow the negative diagonal dominance approach and it allows me to show that in the setting specified above $\delta$-stability depends on E-stability of the aggregate economy which is the upper boundary of aggregate economies with weights of aggregation across agents, $\phi$, and weights of aggregation across endogenous variables, $\psi$.

I have been encouraged by the result that follows from Propositions 2 and 3 in Honkapohja and Mitra (2006) that for stability under heterogeneous RLS or SG learning with the same degrees of inertia, stability in the economy aggregated across agent types (average economy) turns out to be crucial. Following Honkapohja and Mitra (2006), who aggregated an economy across agents by introducing the concept of average (aggregated across agents) economy, I also began to look for the concept of an aggregate economy that has to be crucial for stability of a structurally heterogeneous economy under mixed RLS/SG heterogeneous learning with different degrees of inertia of agents. The basic idea is that there has to be a way to aggregate an economy in an economically reasonable way, so that $E$-stability in the aggregate economy is sufficient for $\delta$-stability in the original economy.

I proceed with aggregation of the economy starting from the following aggregation across agents used by Honkapohja and Mitra (2006):

$$
y_{t}=\alpha+A^{M} \hat{E}_{t}^{A V} y_{t+1}+B w_{t}
$$

It turns out that it is convenient, in addition to the aggregation across agents above, to consider aggregation across endogenous variables. The economy aggregated across endogenous variables will no longer be a vector but a scalar, which means that it can characterize many economies.

I rewrite the formulas used by Honkapohja and Mitra (2006) for average expec- 
tations as

$$
\begin{aligned}
E_{t}^{A V} y_{t+1} & =\left(A^{M}\right)^{-1}\left(S \sum_{h=1}^{S} \frac{1}{S} A_{h} E_{t}^{h} y_{t+1}\right) \\
A_{M} & =S \sum_{h=1}^{S} \frac{1}{S} A_{h}=S \sum_{h=1}^{S} \frac{1}{S} \zeta_{h} \hat{A}_{h} .
\end{aligned}
$$

After this, one can interpret the aggregation done by Honkapohja and Mitra (2006) as follows: first, one takes the weight of each agent type in calculating aggregate expectations of one representative agent to be equal to $\frac{1}{S}$ and then multiplies these expectations by $S$ in order to be consistent with the model that consists of $S$ types of agents. (So that the size of the economy is preserved by replacing each type of agent with a representative agent).

In general, when aggregating expectations one may use different weights for different types of agents that sum up to one in order to reflect the relative importance of a particular agent type expectation in the aggregate economy. So, in my aggregation, I first create a representative agent type by averaging across all agent types (assigning a weight to each type and summing over all types) and then I aggregate over all types by multiplying the representative (average) agent type by $S$ in order to preserve the size of the aggregate economy. ${ }^{13}$

If I write the aggregate economy using different weights for aggregation of expectations across agents, I will get

$$
\begin{aligned}
\hat{E}_{t}^{\text {Weighted }} y_{t+1} & =\left(A^{\text {Weigted }}\right)^{-1}\left(S \sum_{h=1}^{S} \phi_{h} A_{h} \hat{E}_{t}^{h} y_{t+1}\right) \\
A^{\text {Weigted }} & =S \sum_{h=1}^{S} \phi_{h} A_{h}=S \sum_{h=1}^{S} \phi_{h} \zeta_{h} \hat{A}_{h},
\end{aligned}
$$

where $\phi_{h}>0, h=\overline{1, S}$ are weights of single agent types used in calculating aggregate expectations, such that $\sum_{h=1}^{S} \phi_{h}=1$.

\footnotetext{
${ }^{13}$ The new dimension in weighting agent types, in addition to the mass of each agent type $\zeta_{h}$ incorporated in matrices $A_{h}$, may also have the following interpretation. I can assume that the share of each agent type expectation in the average expectations of the population is determined not only by their mass in the population (their physical share), but also by each type's influence, other than their share in the population (e.g., political or mass media power or other type of influence in the social life of the whole population). By assigning additional weights to each agent type I provide a measure of the share of influence of each agent type in the overall expectations, bypassing the intermediate step of measuring the influence of each agent type on other agent types separately.
} 
Next, given the weights of aggregation across endogenous variables $\psi_{i}>0$, $\sum_{i=1}^{n} \psi_{i}=1$, and across agent types $\phi_{h}>0, \sum_{h=1}^{S} \phi_{h}=1$ (and denoting $a_{i j}^{h}$ the element in the $i^{\text {th }}$ row and $j^{\text {th }}$ column of matrix $A_{h}$ ), I aggregate the economy in the following way

$$
\begin{aligned}
& y_{t}^{A G}=\sum_{i} \psi_{i} y_{i t}=\sum_{i} \psi_{i} \alpha_{i}+\sum_{h} S \phi_{h} \sum_{i} \psi_{i} \sum_{j} a_{i j}^{h} \hat{E}_{t}^{h} y_{j t+1}+\left(\sum_{i} \psi_{i} B^{i}\right) w_{t}= \\
& =\sum_{i} \psi_{i} \alpha_{i}+\beta^{A G}(\psi, \phi) \hat{E}_{t}^{A G}\left(y_{t+1}^{A G}\right)+\left(\sum_{i} \psi_{i} B^{i}\right) w_{t} \text {, where } \\
& \beta^{A G}(\psi, \phi)=S \sum_{h} \phi_{h} \sum_{i} \psi_{i} \sum_{j} a_{i j}^{h}, \\
& \hat{E}_{t}^{A G}\left(y_{t+1}^{A G}\right)=(\sum_{h=1}^{S} S \phi_{h} \underbrace{\sum_{j}}_{\beta_{h} \psi_{i} \psi_{i} a_{i j}^{h}})_{h=1}^{-1} S \phi_{h} \underbrace{\sum_{i} \psi_{i} \sum_{j} a_{i j}^{h}}_{\beta_{h}} \hat{E}_{t}^{h} y_{j t+1,}
\end{aligned}
$$

and $B^{i}$ denotes the $i^{\text {th }}$ row of $B$. So, using the derivations above I formulate the following definition.

Definition 2 Given the weights of aggregation across endogenous variables $\psi_{i}>0$, $\sum_{i=1}^{n} \psi_{i}=1$, and across agent types $\phi_{h}>0, \sum_{h=1}^{S} \phi_{h}=1$, the aggregate economy for an economy described by (1), (2) and (3) is defined as

$$
y_{t}^{A G}=\sum_{i} \psi_{i} \alpha_{i}+\beta^{A G}(\psi, \phi) \hat{E}_{t}^{A G}\left(y_{t+1}^{A G}\right)+\left(\sum_{i} \psi_{i} B^{i}\right) w_{t}
$$

(2) and (3),

where $\beta^{A G}(\psi, \phi)$ and $E^{A G}\left(y_{t+1}^{A G}\right)$ are defined in (14) and (15) respectively.

It is also useful to consider an economy that bounds above all possible economies with all possible combinations of signs of $a_{i j}^{h}$ aggregated using weights $\psi$ and $\phi$. This is obviously our original aggregate model written in absolute values. When all elements in the model, $a_{i j}^{h}$, endogenous variables and their expectations are positive, this limiting model exactly coincides with the model considered. So, this is an attainable supremum. Thus I have the following limiting aggregate model:

$$
y_{t}^{A G}=\sum_{i} \psi_{i} y_{i t} \leq y_{t}^{A G \bmod }=\sum_{i} \psi_{i}\left|y_{i t}\right| \leq
$$




$$
\begin{aligned}
\leq \sum_{i} \psi_{i}\left|\alpha_{i}\right|+\beta^{A G \bmod }(\psi, \phi) \hat{E}_{t}^{A G \bmod }\left(y_{t+1}^{A G \bmod }\right)+\left|\left(\sum_{i} \psi_{i} B^{i}\right) w_{t}\right|, \text { where } \\
\beta^{A G \bmod }(\psi, \phi)=S \sum_{h} \phi_{h} \sum_{i} \psi_{i} \sum_{j}\left|a_{i j}^{h}\right| \\
\hat{E}_{t}^{A G \bmod }\left(y_{t+1}^{A G \bmod }\right)=(\sum_{h=1}^{S} S \phi_{h} \underbrace{}_{\beta_{h} \sum_{i} \psi_{i} \sum_{j}\left|a_{i j}^{h}\right|})^{-1} \sum_{h=1}^{S} S \phi_{h} \underbrace{\sum_{i} \psi_{i} \sum_{j}\left|a_{i j}^{h}\right|}_{\beta_{h}} \hat{E}_{t}^{h} \mid y_{j t+1}(17)
\end{aligned}
$$

Definition 3 Given the weights of aggregation across endogenous variables $\psi_{i}>0$, $\sum_{i=1}^{n} \psi_{i}=1$, and across agent types $\phi_{h}>0, \sum_{h=1}^{S} \phi_{h}=1$, the limiting aggregate economy for an economy described by (1), (2) and (3) is defined as

$$
y_{t}^{A G \bmod }=\sum_{i} \psi_{i}\left|\alpha_{i}\right|+\beta^{A G \bmod }(\psi, \phi) \hat{E}_{t}^{A G \bmod }\left(y_{t+1}^{A G \bmod }\right)+\left|\left(\sum_{i} \psi_{i} B^{i}\right) w_{t}\right| \text {, }
$$

(2) and (3),

where $\beta_{a b s}^{A G}(\psi, \phi)$ and $E_{a b s}^{A G}\left(y_{a b s t+1}^{A G}\right)$ are defined in (16) and (17) respectively.

Remark 1 If this limiting aggregate economy is E-stable, then all corresponding aggregate economies with various combinations of signs of $a_{i j}^{h}$ are E-stable.

The structure of this limiting aggregate coefficient $\beta^{A G \text { mod }}$ is as follows. $\sum_{i} \psi_{i}\left|a_{i j}^{h}\right|$ is the coefficient before the expectation of endogenous variable $j$ in the aggregate economy composed of one single agent type $h$. Notice that this coefficient is calculated for the expectation of endogenous variable $j$, that enters the aggregate product with coefficient $\psi_{j}$. So, I may name the ratio $\sum_{i} \psi_{i}\left|a_{i j}^{h}\right| / \psi_{j}$ endogenous variable $j$ "own" expectations relative coefficient. By looking at the values of these coefficients I will be able to judge the weight a particular agent type has in the economy in terms of the aggregate $\beta$-coefficient. The next proposition is formulated in terms of these relative coefficients and stresses the fact that weights of agents in calculating aggregate expectations have to be put into accordance with this economic intuition in order to have stability under heterogeneous learning.

Proposition 3 If there exists at least one pair of vectors of weights for aggregation of endogenous variables $\psi$ and weights $\phi$ for aggregation of agents such that 


\begin{tabular}{||l|l|l|l|l||}
\hline \hline & $r=1$ & $r=2$ & $r=3$ & $r=4$ \\
\hline Subset & $\psi$-any, $\phi$-any & $\psi$-any, $\phi=\frac{1}{S}$ & $\psi=\frac{1}{n}, \phi$-any & $\psi=\frac{1}{n}, \phi=\frac{1}{S}$ \\
\hline$\beta_{r}^{A G \max }=$ & $S \sum_{j} \max _{h, i}\left|a_{i j}^{h}\right|$ & $\max _{i} \sum_{h} \sum_{j}\left|a_{i j}^{h}\right|$ & $S \sum_{i} \max _{h, j}\left|a_{i j}^{h}\right|$ & $\sum_{h} \max _{j} \sum_{i}\left|a_{i j}^{h}\right|$ \\
\hline \hline
\end{tabular}

Table 1: Maximal aggregate $\beta$-coefficients.

for each agent every endogenous variable's "own" expectations relative coefficient is less than the weight of the agent used in calculating aggregate expectations, i.e. $\sum_{i} \psi_{i}\left|a_{i j}^{h}\right| / \psi_{j}<\phi_{h}, \forall j, \forall h$, then the economy described by (1), (2) and (3) is $\delta$ stable.

Proof. See Appendix A.6.

But this proposition above does not give a real rule of thumb (as it implies looking for systems of weights) that could be used to say if a particular economy is stable under heterogeneous learning. For this purpose I have constructed four maximal aggregate $\beta$-coefficients described below. If they are less than one, the economic system is $\delta$-stable.

Thus I go even further looking for upper boundaries by considering not only any possible signs of $a_{i j}$, but also values of weights $\psi$ and $\phi$. These boundaries can be derived for four different subsets of aggregate economies depending on the values of weights $\psi$ and $\phi$ : with arbitrary weights of agents and endogenous variables, and with either equal weights of agents $\frac{1}{S}$ or equal weights of endogenous variables $\frac{1}{n}$, or both. So, each aggregate economy from a particular subset of aggregate economies is bounded above by the following maximal aggregate economy

$$
\begin{aligned}
& y_{t}^{A G}=\sum_{i} \psi_{i} y_{i t} \leq y_{t}^{A G \bmod }=\sum_{i} \psi_{i}\left|y_{i t}\right| \leq y_{t}^{A G \max }= \\
& =\sum_{i} \psi_{i}\left|\alpha_{i}\right|+\beta_{r}^{A G \max } \hat{E}_{t}^{A G \max }\left(y_{t+1}^{A G \max }\right)+\left|\left(\sum_{i} \psi_{i} B^{i}\right) w_{t}\right|, \text { where } \beta_{r}^{A G \max } \text { is de- }
\end{aligned}
$$
fined in Table 1.

First, let us prove that these maximal aggregate $\beta$-coefficients are actually upper boundaries for $\beta^{A G \bmod }(\psi, \phi)=S \sum_{h} \phi_{h} \sum_{i} \psi_{i} \sum_{j}\left|a_{i j}^{h}\right|$ for different subsets of aggregate economies. Formally, the result can be written in a form of the following proposition.

Proposition 4 Maximal aggregate $\beta$-coefficients defined in Table 1 are upper 
boundaries for $\beta^{A G \bmod }(\psi, \phi)=S \sum_{h} \phi_{h} \sum_{i} \psi_{i} \sum_{j}\left|a_{i j}^{h}\right|$ for the corresponding subsets of aggregate economies.

Proof. See Appendix A.6.

Now, it is possible to give the formal definition of the maximal aggregate economy.

Definition 4 Given the weights of aggregation across endogenous variables $\psi_{i}>0$, $\sum_{i=1}^{n} \psi_{i}=1$, and across agent types $\phi_{h}>0, \sum_{h=1}^{S} \phi_{h}=1$, the maximal aggregate economy for an economy described by (1), (2) and (3) is defined as

$$
y_{t}^{A G \max }=\sum_{i} \psi_{i}\left|\alpha_{i}\right|+\beta_{r}^{A G \max }(\psi, \phi) \hat{E}_{t}^{A G \max }\left(y_{t+1}^{A G \max }\right)+\left|\left(\sum_{i} \psi_{i} B^{i}\right) w_{t}\right|,
$$

(2) and (3),

where $\beta_{r}^{A G \max }(\psi, \phi)$ is defined Table 1 and $\hat{E}_{t}^{A G \max }\left(y_{t+1}^{A G \max }\right)$ is defined to be equal to $\hat{E}_{t}^{A G \bmod }\left(y_{t+1}^{A G \bmod }\right)$ in $(17)$.

Notice that each of the above-described boundaries is constructed in such a way that it does not replicate the boundary for a broader set of aggregate models to which this particular model belongs. It is possible to do so by applying the max operator to different groupings of elements of sum and it becomes possible only for a particular subset of aggregate models and which was not possible to apply to a broader set. Under equal $\left|a_{i j}^{h}\right|=|a|$ all these maximal aggregate $\beta$-coefficients coincide with $\beta^{A G \bmod }(\psi, \phi)=n S|a|$. So, these are attainable maxima.

Thus I have managed to aggregate the economy into one dimension and to find the limiting aggregate economies that bound all of such aggregate economies within a particular subset. If one of these limiting aggregate economies is $E$-stable (i.e. if at least one of the maximal aggregate $\beta$-coefficients is less than one), then all aggregate subeconomies from a particular subset of aggregate economies are E-stable. As I have already mentioned the concept of a subeconomy, I shall now introduce its formal definition as this concept is convenient to use in proofs and conditions for $\delta$-stability. 
Definition 5 A subeconomy $\left(h_{1}, \ldots, h_{p}\right)$ of size $p$ for an economy (1) and (2) is defined as consisting only of a part of agents from the original economy:

$$
\begin{aligned}
y_{t} & =\alpha+\sum_{k=1}^{p} A_{i_{k}} \hat{E}_{t}^{h} y_{t+1}+B w_{t}, \\
w_{t} & =F w_{t-1}+v_{t},
\end{aligned}
$$

where $\left(h_{1}, \ldots, h_{p}\right) \subseteq(1, \ldots, S)$ is a set of numbers of agent types present in the subeconomy. A single economy is a particular case of a subeconomy with only one type of agent.

Now I am ready to formulate the result which stresses the key role of $E$-stability in the aggregate economy in stability of the original structurally heterogeneous economy under mixed RLS/SG learning with possibly different degrees of inertia (recall Proposition 2 and Proposition 3 in Honkapohja and Mitra (2006)). The key result is as follows.

Proposition 5 If one of the limiting aggregate economies is E-stable (i.e., one of the maximal aggregate $\beta$-coefficients is less than one), then the economy (1), (2) and (3) is $\delta$-stable. Notice that all subeconomies are also $\delta$-stable under this condition.

Proof. See Appendix A.6.

This result gives a direct rule how to construct $\delta$-stable economies. I think that this is quite a strong result that says that there is one economic unifying condition (such as aggregate $\beta$-coefficient less than one) such that when it holds true all the economies with the same absolute values of $a_{i j}^{h}$ (with all possible combinations of their signs) are $\delta$-stable.

This condition shows how robust is the stability of a model to a change in sign of some coefficients in the economy during the time. Also, fixing certain components in these aggregate $\beta$-coefficients, I may see how the value of other coefficients is flexible for the economy to remain $\delta$-stable. This can be useful in the case when one does not know the exact sign of some coefficient in matrix $A_{h}$, but may estimate that its absolute value belongs to some interval with some probability (the situation typical 
for statistical interval estimation). As an example, the policy maker may know some structural coefficients in the economy and have to choose some parameters itself (like the ones for the policy rule). This formula allows it to see what is the range of parameters it may choose in order to make sure that the economy is $\delta$-stable.

It is possible to simplify the derived conditions for more simple cases, namely, for a univariate model and a structurally homogeneous model.

Proposition 6 A univariate $(n=1)$ economy described by (1) and (2) is $\delta$-stable for any combination of signs of coefficients if and only if $\left|A_{1}\right|+\left|A_{2}\right|+\ldots+\left|A_{s}\right|<1$.

Proof. Obvious: the necessary condition for $\Omega$ to be stable under any $\delta$ is $A_{1}+$ $\ldots+A s<1$ It follows from the condition on the determinant of $-\Omega$, which has to be positive. This determinant equals $-\left(A_{1}+\ldots+A s\right)+1$. For the above condition to hold true for any signs of $A_{h}, h=\overline{1, S}$, it is necessary and sufficient that $\left|A_{1}\right|+$ $\left|A_{2}\right|+\ldots+\left|A_{s}\right|<1$.

Proposition 7 For a structurally homogeneous economy: $A_{h}=\zeta_{h} A, \zeta_{h}>0, \sum_{h=1}^{S} \zeta_{h}=$ $1 ;$ to be $\delta$-stable it is sufficient that at least one of the following limiting aggregate $\beta$-coefficients be less than one; $\max _{i} \sum_{j}\left|a_{i j}\right|$ and $\max _{j} \sum_{i}\left|a_{i j}\right|$.

Proof. Direct application of Proposition 5.

\section{2 "Same Sign" Conditions}

Following the steps of the proof of observation (iv) in Johnson (1974) (the formulation of this observation is presented in Appendix A.5), which is, in fact, the alternative definition of $D$-stability, I get an alternative definition of blocked - diagonal $\left(D_{b}\right)$-stability, that is stability of $D_{b} \Omega$ for any positive blocked-diagonal matrix $D_{b}$. This alternative definition of $D_{b}$-stability is then used to derive conditions for $\delta$-stability.

Definition 6 ( $D_{b}$-stability) Matrix $A$ of size $n S \times n S$ is $D_{b}$-stable if $D_{b} A$ is stable for any positive blocked-diagonal matrix $D_{b}=\operatorname{diag}\left(\delta_{1}, \ldots, \delta_{1}, \ldots, \delta_{S}, \ldots, \delta_{S}\right)$. 
Proposition 8 (Alternative definition of $D_{b}$-stability). Consider $M_{n S}(C)$, the set of all complex $n S \times n S$ matrices, $D_{b n S}$, the set of all $n S \times n S$ blocked-diagonal matrices with positive diagonal entries. Take $A \in M_{n S}(C)$ and suppose that there is $F \in D_{b n S}$ such that $F A$ is stable. Then $A$ is $D_{b}$-stable if and only if $A \pm i D_{b}$ is non-singular for all $D_{b} \in D_{b n S}$. If $A \in M_{n S}(R)$, - the set of all $n S \times n S$ real matrices, then " \pm " in the above condition may be replaced with "+" since, for a real matrix, any complex eigenvalues come in conjugate pairs.

Proof. (The proof is just a modification of the proof of observation (iv) in Johnson (1974) for my blocked-diagonal case) Necessity. Let $A$ be $D_{b}$-stable, that is $E A$ is stable for all positive blocked-diagonal $E \in D_{b n S}$. This means that $\pm i$ cannot be an eigenvalue of matrix $E A$ for any $E \in D_{b n S}$. That is $E A \pm i I$ is non-singular for all $E \in D_{b n S}$, or $A \pm i D_{b}$ is non-singular for all $D_{b}=E^{-1} \in D_{b n S}$. Sufficiency. By contradiction. Let $A$ be not $D_{b}$-stable. Thus, I have that there exists some $E \in D_{b n S}$ such that $F A$ is stable, while $E F A$ is not stable. By continuity, it follows that either value, $\pm i$, is an eigenvalue of $\frac{1}{\alpha}(t E+(1-t) I) F A$ for some $0<t \leq 1$ and $\alpha>0$. So, $A \pm i D_{b}$ is singular for $D_{b}=\alpha F^{-1}(t E+(1-t) I)^{-1} \in D_{b n S}$. Contradiction.

Taking $F$ as an identity matrix, and $D$ as $\operatorname{diag}\left(\frac{1}{\delta_{1}}, \ldots, \frac{1}{\delta_{1}}, \ldots, \frac{1}{\delta_{S}}, \ldots, \frac{1}{\delta_{S}}\right), \delta_{h}>0, h=$ $\overline{1, S}$, in the above proposition, I get the following necessary and sufficient condition (criterion) for $\delta$-stability:

Proposition 9 (criterion for $\delta$-stability in terms of structural and learning heterogeneity) An economy described by (1), (2) and (3) is $\delta$-stable if and only if the corresponding matrix $\Omega$, defined in (11), is stable and

$$
\begin{gathered}
\operatorname{det}\left[\sum_{h=1}^{S}\left(\frac{-\rho_{l} A_{h}}{1+\frac{i}{\delta_{h}}}\right)+I\right]=\operatorname{det}\left[\left(\sum_{h=1}^{S} \frac{1}{1+\frac{1}{\delta_{h}^{2}}}\left(-\rho_{l} A_{h}\right)+I\right) \pm i\left(\sum_{h=1}^{S} \frac{\frac{1}{\delta_{h}}}{1+\frac{1}{\delta_{h}^{2}}}\left(-\rho_{l} A_{h}\right)\right)\right] \neq 0 \\
\forall \delta_{h}>0, h=\overline{1, S}, \forall l=0,1, \ldots, k,\left(\rho_{0}=1\right)
\end{gathered}
$$

For the univariate case $(n=1)$ this condition simplifies to $\Omega-$ stable and

$$
\begin{aligned}
\left(\sum_{h=1}^{S} \frac{1}{1+\frac{1}{\delta_{h}^{2}}}\left(-\rho_{l} A_{h}\right)+1\right) & \neq 0 \text { or } \sum_{h=1}^{S} \frac{\frac{1}{\delta_{h}}}{1+\frac{1}{\delta_{h}^{2}}}\left(-\rho_{l} A_{h}\right) \neq 0, \\
\text { or both, } \forall \delta_{h} & >0, h=\overline{1, S}, \forall l=0,1, \ldots, k,\left(\rho_{0}=1\right) .
\end{aligned}
$$


The alternative definition of $\mathbf{D}$-stability approach allows us to derive the "same sign" conditions for the cases $n=1,2$ and necessary and sufficient conditions for $\delta$-stability for $n=1$.

Proposition 10 (Criterion for $\delta$-stability in the univariate case in terms of structural heterogeneity only) In the case $n=1$, an economy described by (1), (2) and (3) is $\delta$-stable if and only if the corresponding matrix $\Omega$, defined in (11), is stable and at least one of the following holds true: the same sign condition (all $A_{h}$ are greater than or equal to zero and at least one is strictly greater than zero or all $A_{h}$ are less than or equal to zero and at least one is strictly less than zero), or all average economies with $A_{\left(h_{1}, \ldots, h_{p}\right)}=\sum_{\left(h_{1}, \ldots, h_{p}\right)} A_{h}$.corresponding to subeconomies $\left(h_{1}, \ldots, h_{p}\right)$ of all sizes $p$ are not $E$-unstable and for each $l=0,1, \ldots, k\left(\rho_{0}=1\right)$ there exists at least one average economy corresponding to subeconomy $\left(h_{1}^{*}(l), \ldots, h_{p}^{*}(l)\right)$ in each size $p$ for which the stability coefficient $\sum_{\left(h_{1}^{*}(l), \ldots, h_{p}^{*}(l)\right)} \rho_{l} A_{i}$ is strictly less than one.

Remark 2 Due to Proposition 2 of Honkapohja and Mitra (2006), E-stability/instability of a particular average economy is necessary and sufficient for stability/instability of the corresponding subeconomy under transiently heterogeneous SG learning, which is determined by the stability of matrix $\Omega_{\left(h_{1}, . ., h_{p}\right)}$. So, using this criterion, one may use interchangeably the conditions for the stability of average economies or the conditions for stability of subeconomies, whatever is more convenient in a particular setting. By the same Proposition 2 of Honkapohja and Mitra (2006), the condition for stability of matrix $\Omega$ can also be considered as a condition for E-stability of the "largest" (including all agents in calculating the average coefficient) average economy corresponding to the original economy.

Proposition 11 In the case $n=2$, the economy described by (1), (2) and (3) is $\delta$-stable if the corresponding matrix $\Omega$, defined in (11), is stable and the following 
"same sign" condition holds true:

$\operatorname{det}\left(-\rho_{l} A_{i}\right) \geq 0,\left[\operatorname{det} \operatorname{mix}\left(-\rho_{l} A_{i},-\rho_{l} A_{j}\right)+\operatorname{det} \operatorname{mix}\left(-\rho_{l} A_{j},-\rho_{l} A_{i}\right)\right] \geq 0, i \neq j, M_{1}\left(-\rho_{l} A_{i}\right) \geq 0$ or

$\operatorname{det}\left(-\rho_{l} A_{i}\right) \leq 0,\left[\operatorname{det} \operatorname{mix}\left(-\rho_{l} A_{i},-\rho_{l} A_{j}\right)+\operatorname{det} \operatorname{mix}\left(-\rho_{l} A_{j},-\rho_{l} A_{i}\right)\right] \leq 0, i \neq j, M_{1}\left(-\rho_{l} A_{i}\right) \leq 0$, $\forall l=0,1, \ldots, k,\left(\rho_{0}=1\right)$,

where mix $\left(-\rho_{l} A_{i},-\rho_{l} A_{j}\right)$ denotes a matrix of structural parameters of a pairwisemixed economy and is composed by mixing columns of a pair of matrices $\rho_{l} A_{i}, \rho_{l} A_{j}$, for any $i, j=\overline{1, S}$.

Proof. See Appendix A.6.

Remark 3 Unfortunately, though similar "same sign" conditions naturally follow from the alternative definition of $D$-stability for cases $n>2$, stability of $\Omega$ and a similar "same sign" condition are not sufficient for $\delta$-stability in this case. For example, a similar "same sign" condition for case $n=3$ looks like

$$
\begin{aligned}
& M_{3}\left(\operatorname{mix}\left(-\rho_{l} A_{i},-\rho_{l} A_{j},-\rho_{l} A_{k}\right)\right)> 0, M_{2}\left(\operatorname{mix}\left(-\rho_{l} A_{i},-\rho_{l} A_{j}\right)\right)>0, M_{1}\left(-\rho_{l} A_{i}\right)>0 \\
& \text { or } \\
& M_{3}\left(\operatorname{mix}\left(-\rho_{l} A_{i},-\rho_{l} A_{j},-\rho_{l} A_{k}\right)\right)< 0, M_{2}\left(\operatorname{mix}\left(-\rho_{l} A_{i},-\rho_{l} A_{j}\right)\right)<0, M_{1}\left(-\rho_{l} A_{i}\right)<0, \\
& \forall l=0,1, \ldots, k\left(\rho_{0}=1\right)
\end{aligned}
$$

Here, the $M_{n}(\operatorname{mix}())$ operator means the sum of all possible principal minors of size $n$ of a particular mix between matrices.

\section{Necessary Conditions for $\delta$-stability}

The characteristic equation approach (which in my formulation leaves aside the intractable Routh-Hurwitz conditions) has allowed me to derive strong necessary conditions for $\delta$-stability that provide an easy test for non- $\delta$-stability of the model. Note that necessary conditions do not require a diagonal structure of $F$ and $M_{w}$.

Condition $(\star)$ All sums of the same-size principal minors of $D_{1 r}\left(-\Omega_{r}\right)$ are nonnegative for all subeconomies $r=\left(h_{1}, \ldots, h_{p}\right)$ for all $p$ for all positive block-diagonal 
matrices $D_{1 r}$, where $D_{1 r}$ and $\Omega_{r}$ defined similar to $D_{1}$ and $\Omega$ in (11) correspond to a subeconomy of the economy under consideration.

Proposition 12 Necessary condition for $\delta$-stability: For the economy (1) and (2) to be $\delta$-stable, it is necessary that Condition ( $\star$ ) holds true.

Proof. See Appendix A.6.

The condition above can not be used as a test for non- $\delta$-stability, as it requires checking all subeconomies' sums of minors for all possible $D_{1 r}$. That is why below I have constructed a condition that has a direct testing application.

Proposition 13 Necessary condition for $\delta$-stability: For the economy (1) and (2) to be $\delta$-stable, it is necessary that all sums of the same-size principal minors of minus matrices corresponding to subeconomies $\left(-\Omega_{r}\right)$ be non-negative for each corresponding subeconomy $r=\left(h_{1}, \ldots, h_{p}\right)$.

Proof. See Appendix A.6.

I think that this is quite a strong necessary condition, which implies that a lot of models will not satisfy it, and will not be $\delta$-stable. Note that stability of each single economy and subeconomies is a sufficient condition for the condition above to hold true. A weaker requirement that all subeconomies be not unstable (non-positive real parts of eigenvalues) is also sufficient.

\section{Economic Examples}

\section{$5.1 \quad$ Univariate Case}

I exploit the same reduced form used as an example of a univariate model in Honkapohja and Mitra (2006). Such a reduced form can be a result of equilibrium in a non-stochastic basic overlapping generations model (so-called Samuelson model) developed in Chapter 4 of Evans and Honkapohja (2001). Here I develop it for the heterogeneous agents case.

There are $S$ types of agents in the economy, each of whom lives for two periods (young and old). Population is constant: old agents who died in the second period 
are replaced with the same number of young agents in the next period. When agents are young they work supplying labor $n_{h, t}$ and save the revenue obtained from working; when they are old, they consume their savings in amount $c_{h, t+1}$. Output equals labor supply, so wage earned equals the same period price of the consumption good. There is a constant stock of money, $M$, which is the only means of saving in the economy. So, in a non-autarky case, there is trade in the economy between generations: each period $t$, output produced by the young generation is sold to the old agents on a competitive market using money.

Each agent $h$ born at time $t$ has a constant elasticity of substitution utility function

$$
U_{h}\left(c_{h, t+1}, n_{h, t}\right)=\frac{\left(c_{h, t+1}\right)^{1-\sigma_{h}}}{1-\sigma_{h}}-\frac{\left(n_{h, t}\right)^{1+\varepsilon_{h}}}{1+\varepsilon_{h}}, \sigma_{h}, \varepsilon_{h}>0 .
$$

Budget constraints for the first and second periods of the life of agent $h$ are

$$
\begin{aligned}
p_{t} n_{h, t} & =M_{h, t} \\
p_{t+1}^{h, e} c_{h, t+1} & =M_{h, t},
\end{aligned}
$$

respectively, where $p_{t}$ is the price of the good and $M_{h, t}$ denotes the nominal savings of agent $h$ after the first period. $p_{t+1}^{h, e}$ denotes expectations of the next period price made today (they are taken to be point expectations, as the economy considered is non-stochastic).

After solving the agent's problem, the (real) saving function of the agent looks like

$$
F_{h}\left(\frac{p_{t+1}^{h, e}}{p_{t}}\right) \equiv\left(\frac{p_{t+1}^{h, e}}{p_{t}}\right)^{\frac{\sigma-1}{\sigma+\varepsilon}}=\frac{M_{h, t}}{p_{t}} .
$$

The market clearing condition equates total savings to the stock of money in the economy each period

$$
\begin{gathered}
\frac{M}{p_{t}}=\sum_{h=1}^{S} F_{h}\left(\frac{p_{t+1}^{h, e}}{p_{t}}\right)=\sum_{h=1}^{S}\left(\frac{p_{t+1}^{h, e}}{p_{t}}\right)^{\frac{\sigma-1}{\sigma+\varepsilon}}, \text { or } \\
H\left(p_{t},\left(p_{t+1}^{h, e}\right)_{h=1}^{S}\right) \equiv \frac{M}{p_{t}}-\sum_{h=1}^{S} F_{h}\left(\frac{p_{t+1}^{h, e}}{p_{t}}\right)=\frac{M}{p_{t}}-\sum_{h=1}^{S}\left(\frac{p_{t+1}^{h, e}}{p_{t}}\right)^{\frac{\sigma-1}{\sigma+\varepsilon}}=0 .
\end{gathered}
$$


I use Taylor expansion to linearize this condition around the steady state $p_{t+1}=$ $p_{t}=\bar{p}=M / S$,

$$
\tilde{p}_{t}=\sum_{h=1}^{S} \underbrace{\left[-\left.\frac{\partial H}{\partial p_{t}} \frac{\partial H}{\partial p_{t+1}^{h, e}}\right|_{p_{t+1}=p_{t}=\bar{p}}\right.}_{A_{h}} \tilde{p}_{t+1}^{h, e}
$$

$\frac{\partial H}{\partial p_{t}}$ and $\frac{\partial H}{\partial p_{t+1}^{h, e}}$ could be easily calculated using (20) and evaluated at the steady state. Thus,

$$
\begin{aligned}
\left.\frac{\partial H}{\partial p_{t}}\right|_{p_{t+1}=p_{t}=\bar{p}} & =-\frac{M}{\bar{p}^{2}}+\frac{1}{\bar{p}} \sum_{h=1}^{S} F_{h}^{\prime}(1), \\
\left.\frac{\partial H}{\partial p_{t+1}^{h, e}}\right|_{p_{t+1}=p_{t}=\bar{p}} & =-\frac{1}{\bar{p}} F_{h}^{\prime}(1), \text { where } \\
F_{h}^{\prime}(1) & =\frac{\sigma_{h}-1}{\sigma_{h}+\varepsilon_{h}} .
\end{aligned}
$$

So, $A_{h}=\frac{\frac{1-\sigma_{h}}{\sigma_{h}+\varepsilon_{h}}}{S+\sum_{h}\left(\frac{1-\sigma_{h}}{\sigma_{h}+\varepsilon_{h}}\right)} \cdot{ }^{14}$

It is possible to show, using the criterion for $\delta$-stability for univariate economies, that this economy is always $\delta$-stable for any $\epsilon_{h}, \sigma_{h}>0$. Consequently, it is $E$-stable, as well.

Proposition 14 The $O L G$ economy defined above is $\delta$-stable.

Proof. I have $A_{h}=\frac{\frac{1-\sigma_{h}}{\sigma_{h}+\varepsilon_{h}}}{S+\sum_{h}\left(\frac{1-\sigma_{h}}{\sigma_{h}+\varepsilon_{h}}\right)}$ and $\epsilon_{h}, \sigma_{h}>0$. Writing down the second part of the criterion in strict inequalities, I get: $\sum_{h \in\left(h_{1}, \ldots, h_{p}\right)} A_{h}<1 \Longleftrightarrow \frac{\sum_{h \in\left(h_{1}, \ldots, h_{p}\right)} \frac{1-\sigma_{h}}{\sigma_{h}+\varepsilon_{h}}}{\sum_{h=1}^{S} \frac{\epsilon_{h}+1}{\sigma_{h}+\varepsilon_{h}}}-1<0$ $\Longleftrightarrow \frac{-\sum_{h \notin\left(h_{1}, \ldots, h_{p}\right)} \frac{1}{\sigma_{h}+\varepsilon_{h}}-\sum_{h \in\left(h_{1}, \ldots, h_{p}\right)} \frac{\sigma_{h}}{\sigma_{h}+\varepsilon_{h}}-\sum_{h=1}^{S} \frac{\varepsilon_{h}}{\sigma_{h}+\varepsilon_{h}}}{\sum_{h=1}^{S} \frac{\epsilon_{h}+1}{\sigma_{h}+\varepsilon_{h}}}<0$ for any subeconomy $\left(h_{1}, \ldots, h_{p}\right)$ (including the original economy). For $\epsilon_{h}, \sigma_{h}>0$, the condition is always satisfied.

\footnotetext{
${ }^{14}$ Notice, that Honkapohja and Mitra (2006) do not have minus before the first term in (21). My derivations of the reduced form are algebraically analogous to their derivation, and I suspect they lost this minus during derivation. Though their example for values of $A_{h}$ remains valid for this reduced form, the values of $\rho_{h}$ 's in agents CES utiliy functions in their overlapping generations exchange economy could not be found in a plausible range (that is, $\rho_{h}<1$ ) for their specification of $A_{h}{ }^{\prime} \mathrm{s}$.
} 
The behavior around the steady state equilibrium of the OLG exchange economy considered by Honkapohja and Mitra (2006) is presented by the following system of equations:

$$
\begin{aligned}
\tilde{p}_{t} & =\sum_{h=1}^{S} A_{h} \tilde{p}_{t+1}^{h, e}, \text { where } \\
A_{h} & =\frac{F_{h}^{\prime}(1)}{-\frac{M}{\bar{p}}+\sum_{h} F_{h}^{\prime}(1)}, F_{h}^{\prime}(1)=\frac{\omega_{2, h}\left(2-\rho_{h}\right)+\omega_{1, h} \rho_{h}}{4\left(\rho_{h}-1\right)}, \frac{M}{\bar{p}}=\frac{1}{2} \sum_{h}\left(\omega_{1, h}-\omega_{2, h}\right),
\end{aligned}
$$

where $\omega_{1, h}$ and $\omega_{2, h}$ denote the endowment of a single good to the agent of type $h$ for its first and second periods of life, respectively. $\rho_{h}<1$ is a parameter of agent of type $h$ born in period $t$ utility function of consumption in the first and the second periods of its life: $U_{h}\left(c_{h, t}, c_{h, t+1}\right)=\left(c_{h, t}^{\rho_{h}}+c_{h, t+1}^{\rho_{h}}\right)^{1 / \rho_{h}}$.

Similarly to the OLG economy of the Samuelson type considered by me above, it is possible to show that this economy is always E-stable. Moreover, for the specifications satisfying $\omega_{1, h}>\omega_{2, h}$ for all $h=\overline{1, S}$ (all examples of Honkapohja and Mitra (2006) satisfy this specification), the criterion for $\delta$-stability for the univariate economy (Proposition 10) allows me to say that the economy is $\delta$-stable.

Proposition 15 The OLG exchange economy (22) is E-stable. If $\omega_{1, h}>\omega_{2, h}$ for all $h=\overline{1, S}$, it is $\delta$-stable.

Proof. To prove the first part of the proposition, I may use only the condition on the parameters of the utility function, $\rho_{h}<1$ and the condition that $\omega_{1, h}, \omega_{2, h} \geqslant 0$ From the formula for $F_{h}^{\prime}(1)$ I get $\rho_{h}=\frac{2 \omega_{2, h}+4 F_{h}^{\prime}(1)}{4 F_{h}^{\prime}(1)+\omega_{2, h}-\omega_{1, h}}<1$. It leads to inequality $F_{h}^{\prime}(1)<$ $\frac{\omega_{1, h}-\omega_{2, h}}{4}$. Using $\frac{M}{\bar{p}}=\frac{1}{2} \sum_{h=1}^{S}\left(\omega_{1, h}-\omega_{2, h}\right)$, I get $\sum_{h=1}^{S} F_{h}^{\prime}(1)<\frac{M}{2 \bar{p}}$. Next using the formula for $A_{h}$, I get $\sum_{h=1}^{S} F_{h}^{\prime}(1)=\frac{\frac{M}{\bar{p}} \sum A_{h}}{\sum A_{h}-1}<\frac{M}{2 \bar{p}}$. As $\frac{M}{\bar{p}}>0$ (from its economic meaning), I arrive at inequality $\frac{\sum A_{h}+1}{\sum A_{h}-1}<0$ that leads to $-1<\sum_{h=1}^{S} A_{h}<1$. Condition $\sum_{h=1}^{S} A_{h}<1$ is the condition of $E$-stability.

To prove the second part of the proposition, I first express $A_{h}$ via $\rho_{h}, \omega_{1, h}, \omega_{2, h}$. I have $A_{h}=\frac{F_{h}^{\prime}(1)}{-\frac{M}{P}+\sum_{h=1}^{S} F_{h}^{\prime}(1)}$. Substituting for $F_{h}^{\prime}(1)$ and $\frac{M}{P}$ I arrive at $A_{h}=\frac{\frac{\omega_{2, h}+\omega_{1, h}}{1-\rho_{h}}+\omega_{2, h}-\omega_{1, h}}{\sum_{h=1}^{S}\left(\frac{\omega_{2, h}+\omega_{1, h}}{1-\rho_{h}}+\omega_{1, h}-\omega_{2, h}\right)}$. Writing down the second part of the criterion in strict inequalities I get: 


$$
\sum_{h \subseteq\left(h_{1}, \ldots, h_{p}\right)} A_{h}<1 \Longleftrightarrow \frac{-\sum_{h \notin\left(h_{1}, \ldots, h_{p}\right)} \frac{\omega_{2, h}+\omega_{1, h}}{1-\rho_{h}}-\sum_{h=1}^{S}\left(\omega_{1, h}-\omega_{2, h}\right)+\sum_{h \in\left(h_{1}, \ldots, h_{p}\right)}\left(\omega_{2, h}-\omega_{1, h}\right)}{\sum_{h=1}^{S}\left(\frac{\omega_{2, h}+\omega_{1, h}}{1-\rho_{h}}+\omega_{1, h}-\omega_{2, h}\right)}<0
$$

for any subeconomy $\left(h_{1}, \ldots, h_{p}\right)$, including the original economy. Since we have $\rho_{h}<$ $1, \omega_{1, h}>\omega_{2, h} \geq 0$, the condition is always satisfied. Q.E.D.

In addition, I will show how my criterion works for the specification of the reduced form used by Honkapohja and Mitra Honkapohja and Mitra (2006). Let us say that these values of $A_{h}$ are possible for some other model. Honkapohja and Mitra (2006) consider the following specifications: $S=3, A_{1}=0.1, A_{2}=-0.2$ and $A_{3}=-0.5$; $S=3, A_{1}=-15, A_{2}=0.5$ and $A_{3}=0.6 ; S=3, A_{1}=-15, A_{2}=1.1$ and $A_{3}=0.6$.

Since I have been able to derive a criterion for $\delta$-stability in the univariate case, I can say, looking only at the structure of the model, whether it is stable under all types of heterogeneous learning, or not, without looking for examples with various degrees of inertia of agents that violate convergence.

For the first specification, applying the criterion for $\delta$-stability in the univariate case, and finding that the same sign condition is violated, one is left to check the condition for stability of subeconomies: since the setup here is non-stochastic, one is left to check that all average economies corresponding to subeconomies are not unstable and at least one of them is stable, and it can be easily checked by considering stability of the corresponding average economies. $A_{1}=0.1<1, A_{2}=-0.2, A_{3}=$ $-0.5<1, A_{1}+A_{2}=-0.1<1, A_{1}+A_{3}=-0.4<1, A_{2}+A_{3}=-0.7<1, A_{1}+$ $A_{2}+A_{3}=-0.6<1$. So, all average economies corresponding to all subeconomies (including the original economy) are $E$-stable. This means that economy is $\delta$-stable.

For the second specification, using the criterion above, it is clear that the economy will not be $\delta$-stable, as none of the conditions of the criterion is satisfied: the same sign condition is violated, and there exists an average economy corresponding to subeconomy $(2,3)$ for which $A_{(2,3)}=A_{2}+A_{3}=1.1>1$, that is, this average economy is $E$-unstable. Alternatively, one can easily check that eigenvalues of $\Omega_{(2,3)}=\left(\begin{array}{cc}A_{2}-1 & A_{3} \\ A_{2} & A_{3}-1\end{array}\right)=\left(\begin{array}{cc}-0.5 & 0.6 \\ 0.5 & -0.4\end{array}\right)$ are -1 and 0.1 , which violates the stability conditions.

A similar situation is for the third specification. The economy is not $\delta$-stable since the conditions of the criterion are not satisfied: the same sign condition is 
violated, as $A_{h}$ 's have different signs, and there exist average economies corresponding to subeconomies $(2)$ and $(2,3)$ for which $A_{(2)}=A_{2}=1.1>1$ and $A_{(2,3)}=$ $A_{2}+A_{3}=1.7>1$, that is, these average economies are $E$-unstable. Alternatively, one can check that eigenvalues of $\Omega_{(2,3)}=\left(\begin{array}{cc}A_{2}-1 & A_{3} \\ A_{2} & A_{3}-1\end{array}\right)=\left(\begin{array}{cc}0.1 & 0.6 \\ 1.1 & -0.4\end{array}\right)$, and of $\Omega_{(2)}=A_{2}-1=0.1$ are -1 and 0.7 , and 0.1 , respectively, which violates the stability conditions.

In order to further demonstrate the power of the derived criterion for $\delta$-stability, I will consider the case of more than 3 agents in the economy. Let us consider $S=6$, $A_{1}=-0.1, A_{2}=-0.2, A_{3}=-0.5, A_{4}=-15, A_{5}=0.5, A_{6}=0.5$.

The economy under this specification is $\delta$-stable, notwithstanding that the same sign condition is violated and there is an average economy corresponding to subeconomy $(5,6)$ for which $A_{(5,6)}=A_{5}+A_{6}=1$. The condition of the criterion is satisfied. Indeed, all $A_{\left(h_{1}, \ldots, h_{p}\right)}=\sum_{\left(h_{1}, \ldots, h_{p}\right)} A_{h}$ are less or equal than 1 , and for each size $p$ there exists an average economy for which this coefficient is strictly less than one: for $p=1, A_{(1)}=-0.1<1$, for $p=2, A_{(1,2)}=-0.3<1$, for $p=3, A_{(1,2,3)}=$ $-0.8<1$, for $p=4, A_{(1,2,3,4)}=-15.8<1$, for $p=5, A_{(1,2,3,4,5)}=-15.3<1$, for $p=6, A_{(1,2,3,4,5,6)}=-14.8<1$. So, even if the economy contains a subeconomy which is $E$-unstable (lies on the boundary of the stability/instability) and the same sign condition is violated, the whole economy can be $\delta$-stable.

\subsection{Multivariate Case}

I demonstrate the aggregate economy sufficient conditions on a model of simultaneous markets with structural heterogeneity ${ }^{15}$. The idea is to add more economic interpretation to these conditions on an example of a particular multivariate model. ${ }^{16}$

The economic environment is given by the following equation:

$$
p_{t}=l+v d_{t}+\varepsilon_{t}
$$

which is the demand function in matrix form for different goods $j=\overline{1, J}$.

$p_{t}$ is a $J \times 1$ vector of prices, which are endogenous variables in this model, $l$ is a vector of intercepts, $v$ is a $J \times J$ matrix which corresponds to the inverse of the matrix

\footnotetext{
${ }^{15}$ The author expresses sincere thanks to Seppo Honkapohja who suggested to use this example.

${ }^{16} \delta$-stability of a bivariate (New Keynesian) model under two types of optimal monetary policy rules of a policy maker is considered in a companion paper (Bogomolova and Kolyuzhnov (2006)).
} 
of price effects. $d(t)$ is a vector of quantities of the $J$ goods, $\varepsilon_{j, t}=f_{j} \varepsilon_{j, t-1}+v_{j, t}, \varepsilon_{j, t}$ are demand shocks, $\left|f_{j}\right|<1$, and $v_{j, t}$ are independent white noise processes.

There are $S$ types of suppliers with supply functions:

$$
s_{t}^{h}=g^{h}+n^{h} \hat{E}_{t-1}^{h} p_{t}, h=\overline{1, S},
$$

which depend on the expected price due to a production lag. Each supplier produces all $J$ goods. $s(h, t)$ is a $J \times 1$ vector of goods supplied by type $h$ supplier.

It is further assumed that different outputs are produced in independent processes by each producer $h$, so $n^{h}$ is a positive diagonal matrix. Expectations (non-rational, in general) of prices are formed by each supplier at the end of period $t-1$ before the realization of the demand shock $\varepsilon_{t}$.

The market clearing condition, $d_{t}=\sum_{h=1}^{S} s_{t}^{h}$, leads to the following reduced form:

$$
p_{t}=l+v\left(\sum_{i=1}^{S} g^{i}\right)+\sum_{h=1}^{S} v n^{h} \hat{E}_{t-1}^{h} p_{t}+\varepsilon_{t} .
$$

For the case with equal weights of single agent types used in calculating aggregate expectations, the aggregate stability sufficient condition for this model has the form

$$
\sum_{i} \psi_{i}\left|v_{i j}\right|<\frac{\psi_{j}}{S n_{j j}^{h}}, \forall j, h
$$

This condition can be derived by the direct application of Proposition 3 to the given model.

I am going to show now that this sufficient condition for $\delta$-stability at the same time is a sufficient condition for E-stability of the aggregate (univariate) cobweb model. In order to show this, I have to derive, first, the aggregate supply and demand curves using weights of aggregation across agents and expectations I used to derive the sufficient conditions for $\delta$-stability above. 
So, the aggregate demand curve for the price index ${ }^{17}$ can be derived as follows:

$$
\begin{gathered}
P_{t}=\sum_{i} \psi_{i} p_{i t}=\left(\sum_{i} \psi_{i} v_{i 1}\right) d_{1 t}+\ldots+\left(\sum_{i} \psi_{i} v_{i J}\right) d_{J t}+\sum_{i} \psi_{i} l_{i}+\sum_{i} \psi_{i} \varepsilon_{i t}< \\
<\left(\sum_{i} \psi_{i}\left|v_{i 1}\right|\right) d_{1 t}+\ldots+\left(\sum_{i} \psi_{i}\left|v_{i J}\right|\right) d_{J t}+\sum_{i} \psi_{i} l_{i}+\sum_{i} \psi_{i} \varepsilon_{i t}= \\
=\underbrace{\left(\sum_{i} \psi_{i}\left|v_{i 1}\right|+\ldots+\sum_{i} \psi_{i}\left|v_{i J}\right|\right)}_{r_{p}} \underbrace{\left\{\frac{\left(\sum_{i} \psi_{i}\left|v_{i 1}\right|\right) d_{1 t}+\ldots+\left(\sum_{i} \psi_{i}\left|v_{i J}\right|\right) d_{J t}}{\sum_{i} \psi_{i}\left|v_{i 1}\right|+\ldots+\sum_{i} \psi_{i}\left|v_{i J}\right|}\right\}}_{D^{A G}}+\sum_{i} \psi_{i} l_{i}+\sum_{i} \psi_{i} \varepsilon_{i t}= \\
=r_{p} D^{A G}+\sum_{i} \psi_{i} l_{i}+\sum_{i} \psi_{i} \varepsilon_{i t} .
\end{gathered}
$$

Note that here, aggregating over the elements of the price vector, I obtain the demand function in terms of the price index. This is an example of economic interpretation of the aggregation procedure that I propose in my paper, in particular, of assigning weights to the endogenous variables.

To derive the aggregate supply curve for the price index I, first, write the aggregate (over all supplier types) supply equation:

$$
\sum_{h} s_{t}^{h}=\sum_{h} g^{h}+\sum_{h} n^{h} \hat{E}_{t-1}^{h} p_{t}=\sum_{h} g^{h}+\left(\sum_{h} n^{h}\right) \hat{E}_{t-1}^{A G} p_{t} .
$$

Then I write equations for each component of the supply vector: the aggregate supply of each product equations. So, for each product $j$,

$$
\sum_{h} s_{j t}^{h}=\sum_{h} g_{j}^{h}+\left(\sum_{h} n^{h} \hat{E}_{t-1}^{h} p_{t}\right)_{j}=\sum_{h} g_{j}^{h}+\left(n_{11}^{1}+\ldots+n_{J J}^{S}\right) \hat{E}_{t-1}^{a g g r e g} p_{t}^{j} .
$$

Next, I aggregate over all supply equations using weights $\psi_{j}$. Aggregating across endogenous variables (prices) to get the price index, I finally get the aggregate supply

\footnotetext{
${ }^{17}$ To get this function, I aggregate the individual demand functions, not the reduced form equations (in which case I would obtain an equation for the intertemporal equilibrium price index).
} 
curve for the aggregate model

$$
\begin{gathered}
\hat{E}_{t-1}^{A G} P_{t}=\left(\frac{\psi_{1}}{n_{11}^{1}+\ldots n_{11}^{S}}\right) \sum_{h} s_{1 t}^{h}+\ldots+\left(\frac{\psi_{J}}{n_{J J}^{1}+\ldots n_{J J}^{S}}\right) \sum_{h} s_{J t}^{h}-\sum_{j} \psi_{j}\left(\sum_{h} g_{j}^{h} /\left(n_{11}^{1}+\ldots+n_{J J}^{S}\right)\right)= \\
=\underbrace{\left(\frac{\psi_{1}}{n_{11}^{1}+\ldots n_{11}^{S}}+\ldots+\frac{\psi_{J}}{n_{J J}^{1}+\ldots n_{J J}^{S}}\right)}_{r_{m}} \underbrace{\left\{\frac{\left(\frac{\psi_{1}}{n_{11}^{1}+\ldots n_{11}^{S}}\right) \sum_{h} s_{1 t}^{h}+\ldots+\left(\frac{\psi_{J}}{n_{J J}^{1}+\ldots n_{J J}^{S}}\right) \sum_{h} s_{J t}^{h}}{\left(\frac{\psi_{1}}{n_{11}^{1}+\ldots n_{11}^{S}}\right)+\ldots+\left(\frac{\psi_{J}}{n_{J J}^{1}+\ldots n_{J J}^{S}}\right)}\right\}}_{S^{A G}}- \\
-\sum_{j} \psi_{j}\left(\sum_{h} g_{j}^{h} /\left(n_{11}^{1}+\ldots+n_{J J}^{S}\right)\right)= \\
=r_{m} S^{A G}-\sum_{j} \psi_{j}\left(\sum_{h} g_{j}^{h} /\left(n_{11}^{1}+\ldots+n_{J J}^{S}\right)\right) .
\end{gathered}
$$

Thus, we have the following aggregate cobweb model in structural form:

$$
P_{t}=r_{p} D^{A G}+\sum_{i} \psi_{i} l_{i}+\sum_{i} \psi_{i} \varepsilon_{i t} \text { is the aggregate demand curve }
$$

$\hat{E}_{t-1}^{A G} P_{t}=r_{m} S^{A G}-\sum_{j} \psi_{j}\left(\sum_{h} g_{j}^{h} /\left(n_{11}^{1}+\ldots+n_{J J}^{S}\right)\right)$ is the aggregate supply curve,

where

$$
\begin{aligned}
r_{p} & =\sum_{i} \psi_{i}\left|v_{i 1}\right|+\ldots+\sum_{i} \psi_{i}\left|v_{i J}\right| \\
r_{m} & =\left(\frac{\psi_{1}}{n_{11}^{1}+\ldots n_{11}^{S}}+\ldots+\frac{\psi_{J}}{n_{J J}^{1}+\ldots n_{J J}^{S}}\right) .
\end{aligned}
$$

It is clear that from the sufficient condition for $\delta$-stability $\sum_{i} \psi_{i}\left|v_{i j}\right|<\frac{\psi_{j}}{S n_{j j}^{h}}, \forall j, h$, follows $\sum_{i} \psi_{i}\left|v_{i j}\right|<\frac{\psi_{j}}{S \max _{h}\left\{n_{j j}^{h}\right\}}, \forall j$ and, in turn, $\frac{\psi_{j}}{\operatorname{Smax}_{h}\left\{n_{j j}^{h}\right\}}<\frac{\psi_{j}}{n_{j j}^{1}+\ldots n_{j j}^{S}}, \forall j$. Thus, the sufficient condition for $\delta$-stability in this class of models, $\sum_{i} \psi_{i}\left|v_{i j}\right|<\frac{\psi_{j}}{S n_{j j}^{h}}, \forall j, h$, is the condition for $E$-stability of the aggregate cobweb model $\left(r_{m}>r_{p}\right)$.

\section{Conclusion}

My paper to some extent resolves the open question posed by Honkapohja and Mitra (2006). As has been mentioned, Honkapohja and Mitra (2006) provide a general stability condition (criterion) for the case of persistently heterogeneous learning - a joint restriction on matrices of structural parameters and degrees of inertia, which implies that stability in such an economy is determined by the interaction of 
structural heterogeneity and learning heterogeneity. For the general (multivariate) case, however, it was not possible to derive easily interpretable stability conditions expressed in terms of an economy aggregated only across agent types. Honkapohja and Mitra (2006) have derived sufficient conditions in terms of the structure of the economy, but this condition is very general: it requires $D$-stability and $H$-stability of the structural matrices.

In this paper, I attempt to fill this gap and provide easily interpretable sufficient and necessary conditions for such a stability. Based on the analysis of the negative diagonal dominance, the alternative definition of $D$-stability, and the characteristic equation analysis, I have been able to derive two groups of sufficient conditions and one group of necessary conditions for $\delta$-stability, that is, stability under heterogeneous learning, independent of heterogeneity in parameters of learning algorithms. I have found an easily interpretable unifying condition which is sufficient for convergence of an economy under mixed RLS/SG learning with different degrees of inertia towards a rational expectations equilibrium for a broad class of economic models and a criterion for such a convergence in the univariate case. The conditions are formulated using the concept of a subeconomy and a suitably defined aggregate economy.

In particular, using the negative diagonal dominance (sufficient for $D$-stability) and my concept of aggregating an economy (both across agent types and endogenous variables), I have obtained sufficient conditions for $\delta$-stability expressed in terms of $E$-stability of the aggregate economy and its structure. These were summarized as the aggregate economy sufficient conditions. One of them can serve as a rule of thumb for checking a model for $\delta$-stability.

I have found a unifying condition for the most general case of heterogeneous learning in linear forward-looking models. Though it is quite restrictive, my main achievement was to show that such a simple condition with the $E$-stability meaning of some aggregate economy (a notion that has already proved useful as a condition for stability under heterogeneous learning in previous learning literature) does exist for a large class of models. The economic example provided in the end of the paper demonstrates the application of the aggregate economy conditions.

Next, based on the analysis of the alternative definition of $D$-stability, I have 
obtained sufficient conditions on the structure of the economy summarized as the "same sign" conditions. Further, based on the analysis of the characteristic equation and the requirement for negativity of all eigenvalues (necessary and sufficient for stability), I have derived a group of necessary conditions. Their failure can be used as an indicator of non- $\delta$-stability.

Moreover, using the alternative definition of $D$-stability and the characteristic equation approaches, I obtain the criterion for $\delta$-stability in the univariate case. On the example of two types of OLG models I show that this criterion can be easily used to test an economy for $\delta$-stability.

\section{References}

Bogomolova, A. and Kolyuzhnov, D.: 2006, Optimal monetary policy rules: The problem of stability under heterogeneous learning. Manuscript, CERGE-EI.

Evans, G. W. and Honkapohja, S.: 2001, Learning and Expectations in Macroeconomics, Princeton University Press, Princeton, NJ.

Evans, G. W., Honkapohja, S. and Williams, N.: 2005, Generalized stochastic gradient learning, CESifo Working Papers No. 1576.

Giannitsarou, C.: 2003, Heterogeneous learning, Review of Economic Dynamics 6, 885-906.

Honkapohja, S. and Mitra, K.: 2006, Learning stability in economies with heterogeneous agents, Review of Economic Dynamics 9(2), 284-309.

Johnson, C. R.: 1974, Sufficient conditions for d-stability, Journal of Economic Theory $\mathbf{9}, 53-62$.

McCallum, B. T.: 1983, On nonuniqueness in linear rational expectations models: An attempt at perspective, Journal of Monetary Economics 11, 134-168.

Sargent, T. J.: 1993, Bounded Rationality in Macroeconomics, Oxford University Press, Clarendon Press, Oxford and New York. 


\section{A Appendix}

Here I provide the reader with definitions and theorems adapted from mathematics literature that I used for deriving conditions for $\delta$-stability. These results are structured according to the approach which is used for deriving stability conditions.

\section{A.1 General definition of stability and $D$-stability of a ma- trix}

Definition A.1 Matrix $A$ is stable if all the solutions of the system of ordinary differential equations $\dot{x}(t)=A x(t)$ converge toward zero as $t$ converges to infinity.

Theorem A.1 Matrix $A$ is stable if and only if all its eigenvalues have negative real parts.

Definition A.2 (D-stability) Matrix $A$ is D-stable if $D A$ is stable for any positive diagonal matrix $D$.

\section{A.2 Lyapunov theorem approach}

Theorem A.2 (Lyapunov) A real $n \times n$ matrix $A$ is a stable matrix if and only if there exists a positive definite matrix $H$ such that $A^{\prime} H+H A$ is negative definite.

Theorem A.3 (Arrow-McManus, 1958) Matrix $A$ is D-stable if there exists a positive diagonal matrix $C$ such that $A^{\prime} C+C A$ is negative definite.

\section{A.3 Negative diagonal dominance approach}

Definition A.3 (introduced by McKenzie) A real $n \times n$ matrix $A$ is dominant diagonal if there exist $n$ real numbers $d_{j}>0, j=1, \ldots, n$, such that $d_{j}\left|a_{j j}\right|>\sum d_{i}\left|a_{i j}\right|$ : $i \neq j), j=1, \ldots, n$ This is called "column" diagonal dominance. "Row" diagonal dominance is defined as the existence of $d_{i}>0$ such that $d_{i}\left|a_{i i}\right|>\sum d_{j}\left|a_{i j}\right|: j \neq$ $i), i=1, \ldots, n$.

Theorem A.4 (sufficient condition for stability, McKenzie, 1960): If an $n \times n$ matrix $A$ is dominant diagonal and its diagonal is composed of negative elements 
$\left(a_{i i}<0\right.$, all $\left.i=1, \ldots, n\right)$, then the real parts of all its eigenvalues are negative, i.e., $A$ is stable.

Corollary A.1 If A has negative diagonal dominance, then it is D-stable.

\section{A.4 Characteristic equation approach}

Theorem A.5 (Routh-Hurwitz necessary and sufficient conditions for negativity of eigenvalues of a matrix) Consider the following characteristic equation

$$
|\lambda I-A|=\lambda^{n}+b_{1} \lambda^{n-1}+\ldots+b_{n-1} \lambda+b_{n}=0
$$

determining $n$ eigenvalues $\lambda$ of a real $n \times n$ matrix $A$, where $I$ is the identity matrix. Then eigenvalues $\lambda$ all have negative real parts if and only if $\Delta_{1}>0, \Delta_{2}>$ $0, \ldots, \Delta_{n}>0$, where

$$
\Delta_{k}=\left|\begin{array}{ccccccc}
b_{1} & 1 & 0 & 0 & 0 & \cdots & 0 \\
b_{3} & b_{2} & b_{1} & 1 & 0 & \cdots & 0 \\
b_{5} & b_{4} & b_{3} & b_{2} & b_{1} & \cdots & 0 \\
\vdots & \vdots & \vdots & \vdots & \vdots & \ddots & \vdots \\
b_{2 k-1} & b_{2 k-2} & b_{2 k-3} & b_{2 k-4} & b_{2 k-5} & \cdots & b_{k}
\end{array}\right|
$$

\section{A.5 Alternative definition of $D$-stability approach}

Theorem A.6 (From Observation (iv) in Johnson (1974)). Consider $M_{n}(C)$, the set of all complex $n \times n$ matrices, and $D_{n}$, the set of all $n \times n$ diagonal matrices with positive diagonal entries. Take $A \in M_{n}(C)$ and suppose that there is an $F \in D_{n}$ such that $F A$ is stable. Then $A$ is $D$-stable if and only if $A \pm i D$ is non-singular for all $D \in D_{n}$. If $A \in M_{n}(R)$, the set of all $n \times n$ real matrices, then " \pm " in the above condition may be replaced with "+" since, for a real matrix, any complex eigenvalues come in conjugate pairs. 


\section{A.6 Proofs of propositions}

A.6.1 Proof of Proposition 2 (The criterion for stability of a structurally heterogeneous economy under mixed RLS/SG learning for the diagonal environment case under any (possibly different) degrees of inertia of agents, $\delta>0$ )

We have to consider conditions for stability for any positive $\left(\delta_{1}, \ldots, \delta_{S}\right)$ of the following matrices

$$
D_{1} \Omega=\left(\begin{array}{ccc}
\delta_{1} I_{n} & \cdots & 0 \\
\vdots & \ddots & \vdots \\
0 & \cdots & \delta_{S} I_{n}
\end{array}\right)\left(\begin{array}{ccc}
A_{1}-I_{n} & \cdots & A_{S} \\
\vdots & \ddots & \vdots \\
A_{1} & \cdots & A_{S}-I_{n}
\end{array}\right)
$$

and

$$
D_{w} \Omega_{F}=\left(\begin{array}{ccc}
D_{w 1} & \cdots & 0 \\
\vdots & \ddots & \vdots \\
0 & \cdots & D_{w S}
\end{array}\right)\left(\begin{array}{ccc}
F^{\prime} \otimes A_{1}-I_{n k} & \cdots & F^{\prime} \otimes A_{S} \\
\vdots & \ddots & \vdots \\
F^{\prime} \otimes A_{1} & \cdots & F^{\prime} \otimes A_{S}-I_{n k}
\end{array}\right)
$$

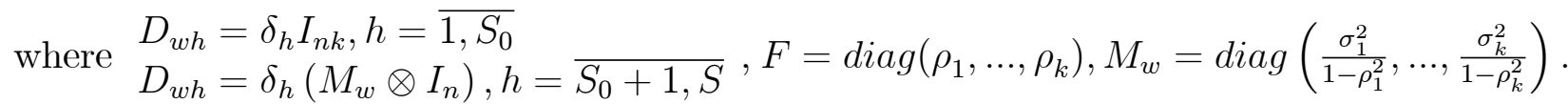

The expression for $D_{w} \Omega_{F}$ in the diagonal case looks as follows

$$
\begin{aligned}
& D_{w} \Omega_{F}=\left(\begin{array}{ccc}
D_{w 1} & \cdots & 0 \\
\vdots & \ddots & \vdots \\
0 & \cdots & D_{w S}
\end{array}\right)\left(\begin{array}{ccc}
F^{\prime} \otimes A_{1}-I_{n k} & \cdots & F^{\prime} \otimes A_{S} \\
\vdots & \ddots & \vdots \\
F^{\prime} \otimes A_{1} & \cdots & F^{\prime} \otimes A_{S}-I_{n k}
\end{array}\right)= \\
& =\operatorname{diag}(\underbrace{\delta_{1}, \ldots, \delta_{1}}_{n k}, \ldots, \underbrace{\delta_{S_{0}}, \ldots, \delta_{S_{0}}}_{n k}, \underbrace{\frac{\delta_{S_{0}+1} \sigma_{1}^{2}}{1-\rho_{1}^{2}}, \ldots, \frac{\delta_{S_{0}+1} \sigma_{1}^{2}}{1-\rho_{1}^{2}}}_{n}, \ldots, \underbrace{\frac{\delta_{S_{0}+1} \sigma_{k}^{2}}{1-\rho_{k}^{2}}, \ldots, \frac{\delta_{S_{0}+1} \sigma_{k}^{2}}{1-\rho_{k}^{2}}}_{n}, \ldots
\end{aligned}
$$

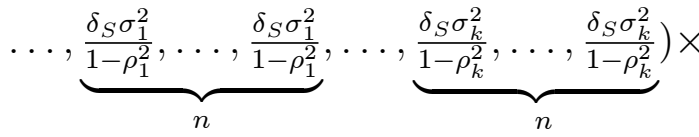

$$
\begin{aligned}
& \times\left(\begin{array}{ccccccc}
\rho_{1} A_{1}-I_{n} & \cdots & 0 & \cdots & \rho_{1} A_{S} & \cdots & 0 \\
\vdots & \ddots & \vdots & \cdots & \vdots & \ddots & \vdots \\
0 & \cdots & \rho_{k} A_{1}-I_{n} & \cdots & 0 & \cdots & \rho_{k} A_{S} \\
\vdots & \vdots & \vdots & \ddots & \vdots & \vdots & \vdots \\
\rho_{1} A_{1} & \cdots & 0 & \cdots & \rho_{1} A_{S}-I_{n} & \cdots & 0 \\
\vdots & \ddots & \vdots & \cdots & \vdots & \ddots & \vdots \\
0 & \cdots & \rho_{k} A_{1} & \cdots & 0 & \cdots & \rho_{k} A_{S}-I_{n}
\end{array}\right) .
\end{aligned}
$$


After some permutations of rows and columns that do not change the absolute value of the determinant of $D_{w} \Omega_{F}-\mu I$, I obtain that the following characteristic equation for eigenvalues $\mu$ of $D_{w} \Omega_{F}$

$$
\operatorname{det}\left[D_{w} \Omega_{F}-\mu I\right]=0
$$

is equivalent to

$$
\begin{aligned}
& 0=\operatorname{det}\left[\operatorname { d i a g } \left((\underbrace{\delta_{1}, \ldots, \delta_{1}}_{n}, \ldots, \underbrace{\delta_{S_{0}}, \ldots, \delta_{S_{0}}}_{n}, \underbrace{\frac{\delta_{S_{0}+1} \sigma_{1}^{2}}{1-\rho_{1}^{2}}, \ldots, \frac{\delta_{S_{0}+1} \sigma_{1}^{2}}{1-\rho_{1}^{2}}}_{n}, \ldots, \underbrace{\left.\frac{\delta_{S} \sigma_{1}^{2}}{1-\rho_{1}^{2}}, \ldots, \frac{\delta_{S} \sigma_{1}^{2}}{1-\rho_{1}^{2}}\right)}_{n}, \ldots\right.\right. \\
& \ldots,(\underbrace{\delta_{1}, \ldots, \delta_{1}}_{n}, \ldots, \underbrace{\delta_{S_{0}}, \ldots, \delta_{S_{0}}}_{n}, \underbrace{\frac{\delta_{S_{0}+1} \sigma_{k}^{2}}{1-\rho_{k}^{2}}, \ldots, \frac{\delta_{S_{0}+1} \sigma_{k}^{2}}{1-\rho_{k}^{2}}}_{n}, \ldots, \underbrace{\left.\frac{\delta_{S} \sigma_{k}^{2}}{1-\rho_{k}^{2}}, \ldots, \frac{\delta_{S} \sigma_{k}^{2}}{1-\rho_{k}^{2}}\right)}_{n}) \times \\
& \times \operatorname{diag}\left(\left[\begin{array}{ccc}
\rho_{1} A_{1}-I_{n}-\frac{\mu I_{n}}{\delta_{1}} & \cdots & \rho_{1} A_{S} \\
\vdots & \ddots & \vdots \\
\rho_{1} A_{1} & \cdots & \rho_{1} A_{S}-I_{n}-\frac{\left(1-\rho_{1}^{2}\right) \mu I_{n}}{\delta_{S} \sigma_{1}^{2}}
\end{array}\right], \ldots\right. \\
& \left.\left.\ldots,\left[\begin{array}{ccc}
\rho_{k} A_{1}-I_{n}-\frac{\mu I_{n}}{\delta_{1}} & \cdots & \rho_{k} A_{S} \\
\vdots & \ddots & \vdots \\
\rho_{k} A_{1} & \cdots & \rho_{k} A_{S}-I_{n}-\frac{\left(1-\rho_{k}^{2}\right) \mu I_{n}}{\delta_{S} \sigma_{k}^{2}}
\end{array}\right]\right)\right]
\end{aligned}
$$

or, in matrix form:

$$
0=\operatorname{det}\left[\begin{array}{cc}
\tilde{D}_{1} \Omega_{\rho_{1}}-\mu I_{n S} & \\
& \tilde{D}_{k} \Omega_{\rho k}-\mu I_{n S}
\end{array}\right]=\prod_{l=1}^{k} \operatorname{det}\left[\tilde{D}_{l} \Omega_{\rho_{l}}-\mu I_{n S}\right],
$$

where

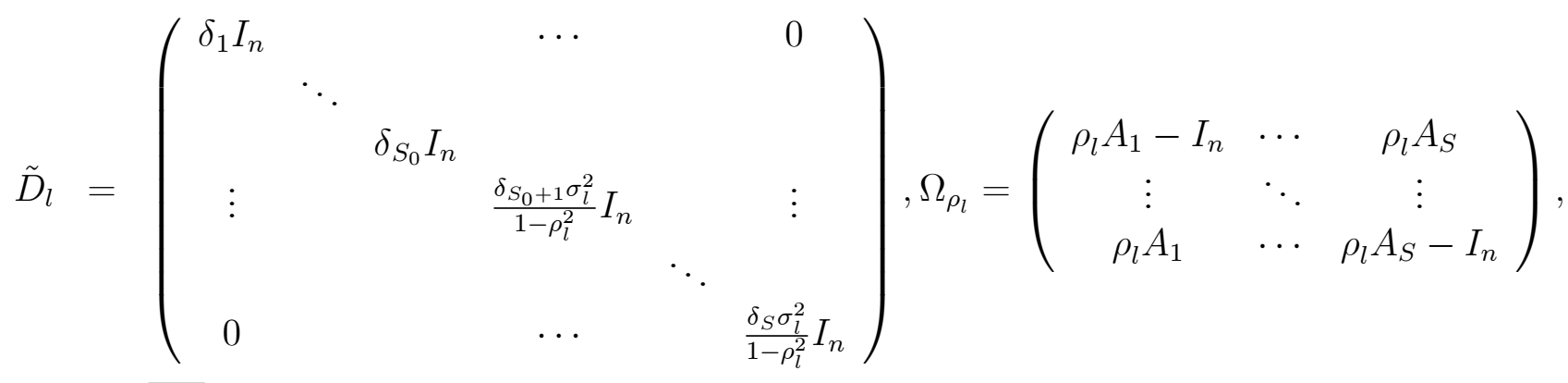

$$
\begin{aligned}
& l=\overline{1, k} \text {. }
\end{aligned}
$$

Thus, the analysis of stability of $D_{w} \Omega_{F}$, defined in (11), is equivalent to the analysis of stability of $\tilde{D}_{l} \Omega_{\rho_{l}}, \forall l=\overline{1, k}$. 
So, the analysis of the stability of $D_{w} \Omega_{F}$ can be split into the analysis of the stability of the unrelated matrix blocks. Changing notation $\delta_{h}:=\frac{\delta_{h} \sigma_{l}^{2}}{1-\rho_{l}^{2}}>0$ for $h=\overline{S_{0}+1, S}$ for each case $l=\overline{1, k}$, I obtain that the analysis of stability of $D_{w} \Omega_{F}$ for any $\delta>0$ is equivalent to the analysis of stability of $k$ matrices $D_{1} \Omega_{\rho_{l}}$. Introducing notation $\rho_{0}=1$, I can write the general criterion for stability of a structurally heterogeneous economy under mixed RLS/SG learning for the diagonal environment case under any (possibly different) degrees of inertia of agents, $\delta>0$ as follows: $D_{1} \Omega_{\rho_{l}}$ is stable for all $l=0,1, \ldots, k$. Q.E.D.

\section{A.6.2 Proof of Proposition 3}

Use "columns" negative diagonal dominance of $\Omega_{\rho_{l}}$, which is sufficient for the real parts of eigenvalues of $D_{1} \Omega_{\rho_{l}}$ to be negative; look for a condition which would be sufficient for negative diagonal dominance in this setup. As weights for rows use $\left(\phi_{1}\left(\psi_{1}, \ldots, \psi_{n}\right), \ldots, \phi_{s}\left(\psi_{1}, \ldots, \psi_{n}\right)\right), \phi_{i}>0, \psi_{h}>0, \sum_{i} \psi_{i}=1, \sum_{h} \phi_{h}=1$.

For any $l$ take any block $h$ and any column $j$

$$
\begin{aligned}
& \left\{\begin{array}{l}
\rho_{l} a_{j j}^{h}-1<0-\text { negative diagonal } \\
\phi_{h} \psi_{j}\left|\rho_{l} a_{j j}^{h}-1\right|>\left(\phi_{1}+\ldots+\phi_{s}\right) \sum_{i} \psi_{i}\left|\rho_{l} a_{i j}^{h}\right|-\phi_{h} \psi_{j}\left|\rho_{l} a_{j j}^{h}\right| \text { - dominance } \forall j, \forall h, \forall l
\end{array}\right. \\
& \left\{\begin{array}{l}
\rho_{l} a_{j j}^{h}-1<0 \\
-\phi_{h} \psi_{j} \rho_{l} a_{j j}^{h}+\phi_{h} \psi_{j}>\left(\phi_{1}+\ldots+\phi_{s}\right) \sum_{i} \psi_{i}\left|\rho_{l} a_{i j}^{h}\right|-\phi_{h} \psi_{j}\left|\rho_{l} a_{j j}^{h}\right| \forall j, \forall h, \forall l
\end{array}\right. \\
& \text { Case } 1\left\{\begin{array}{l}
0 \leq \rho_{l} a_{j j}^{h}<1 \\
\sum_{i} \psi_{i}\left|\rho_{l} a_{i j}^{h}\right|<\underbrace{\frac{\phi_{h} \psi_{j}}{\phi_{1}+\ldots+\phi_{S}}}_{=1} \forall j, \forall h, \forall l
\end{array}\right. \\
& \text { Case } 2\left\{\begin{array}{l}
\rho_{l} a_{j j}^{h}<0 \\
\sum_{i} \psi_{i}\left|\rho_{l} a_{i j}^{h}\right|<\underbrace{\frac{\phi_{h} \psi_{j}}{\phi_{1}+\ldots+\phi_{S}}}_{=1}-\underbrace{\frac{2 \varphi_{h} \psi_{j}}{\phi_{1}+\ldots+\phi_{S}}}_{=1} \rho_{l} a_{j j}^{h} \forall j, \forall h, \forall l
\end{array}\right.
\end{aligned}
$$

Since in the second case $\rho_{l} a_{j j}^{h}<0$, one may formulate the following sufficient condition $\sum_{i} \psi_{i}\left|\rho_{l} a_{i j}^{h}\right|<\phi_{h} \psi_{j} \forall j, \forall h, \forall l$. The condition $1>\rho_{l} a_{j j}^{h}$ is implied by this relation, and the condition of case 2 is also satisfied. To prove that $1>\rho_{l} a_{j j}^{h}$, notice that $\sum_{i} \psi_{i}\left|\rho_{l} a_{i j}^{h}\right|<\phi_{h} \psi_{j} \Longrightarrow \underbrace{\frac{\sum_{i \neq j} \psi_{i}\left|\rho_{l} a_{i j}^{h}\right|}{\psi_{j}}}_{>0}+\underbrace{\left|\rho_{l} a_{j j}^{h}\right|}_{>0}<\phi_{h}<1 \Longrightarrow\left|\rho_{l} a_{j j}^{h}\right|<1 \Longrightarrow$ $\rho_{l} a_{j j}^{h}<1$. 
As $\left|\rho_{l}\right|<1$, the derived sufficient condition follows from $\sum_{i} \psi_{i}\left|a_{i j}^{h}\right|<\phi_{h} \psi_{j} \forall j, \forall h$, that is, the condition for $l=0\left(\rho_{0}=1\right)$. So this condition alone is sufficient for $\delta-$ stability. This is the condition of Proposition 2. Q.E.D.

\section{A.6.3 Proof of Proposition 4}

1. $\left.\beta^{A G \bmod }(\psi, \phi)\right|_{\substack{\phi-a n y \\ \psi-\text { any }}}=S \sum_{h} \phi_{h} \sum_{i} \psi_{i} \sum_{j}\left|a_{i j}^{h}\right| \leq$

$$
\leq S \sum_{h} \phi_{h} \sum_{j} \sum_{i} \psi_{i} \max _{h, i}\left|a_{i j}^{h}\right|=S \sum_{j} \underbrace{\left(\sum_{h} \sum_{i} \phi_{h} \psi_{i}\right)}_{=1} \max _{h, i}\left|a_{i j}^{h}\right|=\beta_{1}^{A G \max } .
$$

2. $\left.\beta^{A G \bmod }(\psi, \phi)\right|_{\substack{\phi-a n y \\ \psi=\frac{1}{S}}}=S \sum_{h} \underbrace{\frac{1}{S}}_{\phi_{h}} \sum_{i} \psi_{i} \sum_{j}\left|a_{i j}^{h}\right|=\sum_{h} \sum_{i} \psi_{i} \sum_{j}\left|a_{i j}^{h}\right| \leq$

$$
\leq \underbrace{\left(\sum_{i} \psi_{i}\right)}_{=1} \max _{i} \sum_{h} \sum_{j}\left|a_{i j}^{h}\right|=\beta_{2}^{A G \max }
$$

3. $\left.\beta^{A G \bmod }(\psi, \phi)\right|_{\substack{\phi=\frac{1}{n} \\ \psi-a n y}}=S \sum_{h} \phi_{h} \sum_{i} \underbrace{\frac{1}{n}}_{\psi_{i}} \sum_{j}\left|a_{i j}^{h}\right| \leq S \sum_{i} \frac{1}{n} \sum_{h} \sum_{j} \phi_{h} \max _{h, j}\left|a_{i j}^{h}\right|=$

$$
=S \sum_{i} \frac{1}{n} \max _{h, j}\left|a_{i j}^{h}\right| \underbrace{\left(\sum_{h} \sum_{j} \phi_{h}\right)}_{=n}=S \sum_{i} \max _{h, j}\left|a_{i j}^{h}\right|=\beta_{3}^{A G \max }
$$

4. $\left.\beta^{A G \bmod }(\psi, \phi)\right|_{\substack{\phi=\frac{1}{n} \\ \psi=\frac{1}{S}}}=S \sum_{h} \underbrace{\frac{1}{S}}_{\phi_{h}} \sum_{i} \underbrace{\frac{1}{n}}_{\psi_{i}} \sum_{j}\left|a_{i j}^{h}\right|=\sum_{h} \sum_{i} \frac{1}{n} \sum_{j}\left|a_{i j}^{h}\right| \leq$

$$
\leq \sum_{h} \frac{1}{n} \sum_{j} \max _{j} \sum_{i}\left|a_{i j}^{h}\right|=\sum_{h} \max _{j} \sum_{i} \mid a_{i j}^{h} \underbrace{\frac{1}{n} \sum_{j} 1}_{=1}=\beta_{4}^{A G \max }, \text { Q.E.D. }
$$

\section{A.6.4 Proof of Proposition 5}

1. for $\beta_{1}^{A G \max }$ :

We have $\beta_{1}^{A G \max }=S \sum_{j} \max _{h, i}\left|a_{i j}^{h}\right|<1$ and have to prove that there exist weights $\psi$ and $\phi$ such that $\frac{\sum_{i} \psi_{i}\left|a_{i j}^{h}\right|}{\psi_{j}}<\phi_{h} \forall j, \forall h$.

Let us take $\phi_{h}=\frac{1}{S} \forall h$, and $\psi_{j}=S \max _{h, i}\left|a_{i j}^{h}\right|+\frac{\overbrace{1-S \sum_{j} \max _{h, i}\left|a_{i j}^{h}\right|}^{>0}}{n} \forall j$. These can 
be considered as weights since $\sum_{h=1}^{S} \phi_{h}=1,0<\phi_{h}<1$ and $\sum_{j=1}^{n} \psi_{j}=1,0<\psi_{j}<1$.

Notice that $\frac{\psi_{j}}{S}>\max _{h, i}\left|a_{i j}^{h}\right|=\sum_{i} \psi_{i} \max _{h, i}\left|a_{i j}^{h}\right|>\sum_{i} \psi_{i}\left|a_{i j}^{h}\right|, \forall j, \forall h$, or, after rewriting: $\sum_{i} \psi_{i}\left|a_{i j}^{h}\right|<\psi_{j} \underbrace{\phi_{h}}_{=\frac{1}{S}}, \forall j, \forall h$.

4. for $\beta_{4}^{A G \max }$ :

We have $\beta_{4}^{A G \max }=S \sum_{h} \max _{j} \sum_{i}\left|a_{i j}^{h}\right|<1$ and have to prove that there exist weights $\psi$ and $\phi$ such that $\frac{\sum_{i} \psi_{i}\left|a_{i j}^{h}\right|}{\psi_{j}}<\phi_{h} \forall j, \forall h$.

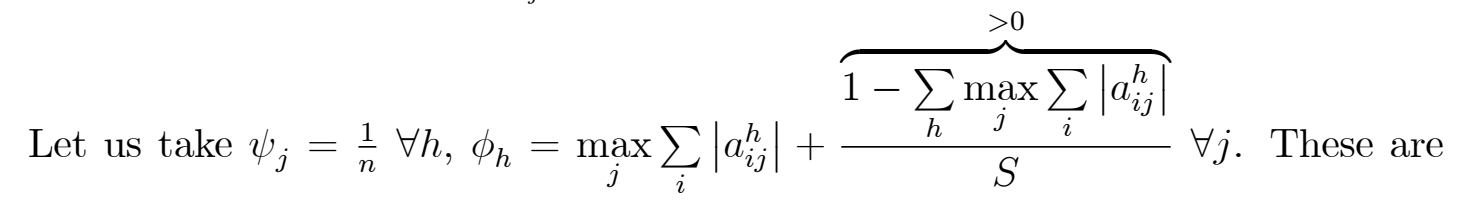
weights as $\sum_{h=1}^{S} \phi_{h}=1,0<\phi_{h}<1$ and $\sum_{j=1}^{S} \psi_{j}=1,0<\psi_{j}<1$.

Notice that $\phi_{h}>\max _{j} \sum_{i}\left|a_{i j}^{h}\right|>\sum_{i}\left|a_{i j}^{h}\right|, \forall j, \forall h$, or, after rewriting: $\frac{\sum_{i} \overbrace{\psi_{i}}^{\frac{1}{n}}\left|a_{i j}^{h}\right|}{\underbrace{\psi_{j}}_{\frac{1}{n}}}=$ $\sum_{i} \psi_{i}\left|a_{i j}^{h}\right|<\phi_{h}, \forall j, \forall h$

To prove the proposition for $\beta_{2}^{A G \max }$ and $\beta_{3}^{A G \max }$, I first derive a sufficient condition for $\delta$ - stability that follows from the "rows" diagonal dominance condition, which is also sufficient for stability of matrices $D_{1} \Omega_{\rho l}$. Therefore my derivation of this condition resembles the steps in the proof of Proposition 2. As weights for columns use $\left(d_{1}, \ldots, d_{n}, \ldots, d_{1}, \ldots, d_{n}\right), d_{i}>0, \sum_{i} d_{i}=1$

For any $l$ take any block $h$ and any row $i$.

$$
\begin{aligned}
& \left\{\begin{array}{l}
\rho_{l} a_{i i}^{h}-1<0-\text { negative diagonal } \\
d_{i}\left|\rho_{l} a_{i i}^{h}-1\right|>\sum_{h} \sum_{j} d_{j}\left|\rho_{l} a_{i j}^{h}\right|-d_{i}\left|\rho_{l} a_{i i}^{h}\right| \text { - dominance } \forall i, \forall h, \forall l
\end{array}\right. \\
& \left\{\begin{array}{l}
\rho_{l} a_{i i}^{h}-1<0 \\
-d_{i} \rho_{l} a_{i i}^{h}+d_{i}>\sum_{h} \sum_{j} d_{j}\left|\rho_{l} a_{i j}^{h}\right|-d_{i}\left|\rho_{l} a_{i i}^{h}\right| \quad \forall i, \forall h, \forall l
\end{array}\right. \\
& \text { Case } 1\left\{\begin{array}{l}
0 \leq \rho_{l} a_{i i}^{h}<1 \\
\sum_{h} \sum_{j} d_{j}\left|\rho_{l} a_{i j}^{h}\right|<d_{i} \quad \forall i, \forall h, \forall l
\end{array}\right.
\end{aligned}
$$


Case $2\left\{\begin{array}{l}\rho_{l} a_{i i}^{h}<0 \\ \sum_{h} \sum_{j} d_{j}\left|\rho_{l} a_{i j}^{h}\right|<d_{i}-2 d_{i} \rho_{l} a_{i i}^{h} \quad \forall i, \forall h, \forall l\end{array}\right.$

Since in the second case $\rho_{l} a_{i i}^{h}<0$, one may formulate the following sufficient condition $\sum_{h} \sum_{j} d_{j}\left|\rho_{l} a_{i j}^{h}\right|<d_{i} \forall i, \forall h, \forall l$. The condition $1>\rho_{l} a_{i i}^{h}$ is implied by this relation, and the condition of case 2 is also satisfied. To prove that $1>\rho_{l} a_{i i}^{h}$, notice that $\sum_{h} \sum_{j} d_{j}\left|\rho_{l} a_{i j}^{h}\right|<d_{i} \Longrightarrow \underbrace{\sum_{h} \sum_{j \neq i} d_{j}\left|\rho_{l} a_{i j}^{h}\right|}_{>0}+\underbrace{\sum_{h} d_{i}\left|\rho_{l} a_{i i}^{h}\right|}_{>0}<d_{i}<1 \Longrightarrow$ $\left|\rho_{l} a_{i i}^{h}\right|<1 \Longrightarrow \rho_{l} a_{i i}^{h}<1$.

As $\left|\rho_{l}\right|<1$, the derived sufficient condition follows from $\sum_{h} \sum_{j} d_{j}\left|a_{i j}^{h}\right|<d_{i} \forall i, \forall h$, that is, the condition for $l=0\left(\rho_{0}=1\right)$. So this condition alone is sufficient for $\delta$-stability.

Next I use the derived sufficient condition to prove Proposition 2 for $\beta_{\max }^{2}$ and $\beta_{\max }^{3}$.

2. for $\beta_{2}^{A G \max }$ :

We have $\beta_{2}^{A G \max }=\max _{i} \sum_{h} \sum_{j}\left|a_{i j}^{h}\right|<1$ and have to prove that there exist weights $d=\left(d_{1}, \ldots, d_{n}, \ldots, d_{1}, \ldots, d_{n}\right), d_{i}>0, \sum_{i} d_{i}=1$, such that $\sum_{h} \sum_{j} d_{j}\left|a_{i j}^{h}\right|<d_{i} \forall i, \forall h$.

Let us take $d_{j}=\frac{1}{n} \forall j$.

Notice that $\sum_{h} \sum_{j}\left|a_{i j}^{h}\right|<\max _{i} \sum_{h} \sum_{j}\left|a_{i j}^{h}\right|<1, \forall i, \forall h$, or, after rewriting: $\sum_{h} \sum_{j} \underbrace{\frac{1}{n}}_{d_{j}}\left|a_{i j}^{h}\right|<$ $\underbrace{\frac{1}{n}}_{d_{i}}, \forall i, \forall h$

3. for $\beta_{3}^{A G \max }$ :

We have $\beta_{3}^{A G \max }=S \sum_{h} \max _{h, j}\left|a_{i j}^{h}\right|<1$ and have to prove that there exist weights $d=\left(d_{1}, \ldots, d_{n}, \ldots, d_{1}, \ldots, d_{n}\right), d_{i}>0, \sum_{i} d_{i}=1$ such that $\sum_{h} \sum_{j} d_{j}\left|a_{i j}^{h}\right|<d_{i} \forall i, \forall h$.

Let us take $d_{i}=S \max _{h, j}\left|a_{i j}^{h}\right|+\frac{\overbrace{1-S \sum_{i} \max _{h, j}\left|a_{i j}^{h}\right|}^{>0}}{n} \forall i$. These can be taken as weights since $\sum_{i=1}^{n} d_{i}=1,0<d_{i}<1$.

Notice that $d_{i}>S \max _{h, j}\left|a_{i j}^{h}\right|=\underbrace{\sum_{j=1}^{n} d_{j}}_{=1} \underbrace{\sum_{h=1}^{S}}_{=S} \max _{h, j}\left|a_{i j}^{h}\right|>\sum_{h} \sum_{j} d_{j}\left|a_{i j}^{h}\right|, \forall i, \forall h$. 


\section{A.6.5 Proof of Proposition 10}

For the case of $n=1$, the condition for the alternative definition of $D$-stability simplifies the requirement for $\Omega$ to be stable and for at least one of the following to hold true

$$
\begin{aligned}
& \left(\frac{\frac{1}{\delta_{1}}}{1+\frac{1}{\delta_{1}^{2}}}\left(-\rho_{l} A_{1}\right)+\ldots+\frac{\frac{1}{\delta_{S}}}{1+\frac{1}{\delta_{S}^{2}}}\left(-\rho_{l} A_{S}\right)\right) \neq 0, \\
& \left(\frac{1}{1+\frac{1}{\delta_{1}^{2}}}\left(-\rho_{l} A_{1}\right)+\ldots+\frac{1}{1+\frac{1}{\delta_{S}^{2}}}\left(-\rho_{l} A_{S}\right)+1\right) \neq 0 \text { for all } l=0,1, \ldots, k\left(\rho_{0}=1\right) .
\end{aligned}
$$

The first "same sign" condition follows directly from the first inequality above. The second condition that follows from the second inequality is proved below.

Necessity: Follows directly from the proof of Proposition 12. Just note that in the univariate economy setup any sum of minors $M_{k}$ consists of elements $\delta_{h_{1}} \delta_{h_{2}} \ldots \delta_{h_{k}}\left(-\rho_{l} A_{h_{1}}-\right.$ $\left.\rho_{l} A_{h_{2}}-\ldots-\rho_{l} A_{h_{k}}+1\right)$ and that if the sum of nonnegative elements is strictly greater than zero, then at least one of them has to be strictly positive.

Sufficiency: I have $-\rho_{l} A_{h_{1}}-\rho_{l} A_{h_{2}}-\ldots-\rho_{l} A_{h_{p}}+1 \geq 0$ for any subeconomy $\left(h_{1}, \ldots, h_{p}\right)$ and for each group of subeconomies of size $p, \exists h_{1}^{*}(l), \ldots, h_{p}^{*}(l):-\rho_{l} A_{h_{1}^{*}}-$ $\rho_{l} A_{h_{2}^{*}}-\ldots-\rho_{l} A_{h_{p}^{*}}+1>0$, and have to prove that $\left(\frac{1}{1+\frac{1}{\delta_{1}^{2}}}\left(-\rho_{l} A_{1}\right)+\ldots+\frac{1}{1+\frac{1}{\delta_{S}^{2}}}\left(-\rho_{l} A_{S}\right)+1\right) \neq$ 0 .

I group separately the terms corresponding to non-positive $\rho_{l} A_{i}$ 's and terms corresponding to strictly positive $\rho_{l} A_{i}$ 's.

Schematically, I will have

$$
\underbrace{\left[\frac{1}{1+\frac{1}{\delta_{1}^{2}}}\left(\rho_{l} A_{1}^{-}\right)+\ldots+\frac{1}{1+\frac{1}{\delta_{k}^{2}}}\left(\rho_{l} A_{k}^{-}\right)\right]}_{\leq 0}+\underbrace{\left[\frac{1}{1+\frac{1}{\delta_{1}^{2}}}\left(\rho_{l} A_{1}^{+}\right)+\ldots+\frac{1}{1+\frac{1}{\delta_{m}^{2}}}\left(\rho_{l} A_{m}^{+}\right)\right]}_{\leq 1}-
$$

1. If the first sum is strictly less than zero, then the whole expression is less than zero. If the first sum is equal to zero, then the second sum (if there are any positive $\rho_{l} A^{\prime}$ s at all) has to be less than 1: for the whole economy I have to have that $-\rho_{l} A_{1}-\rho_{l} A_{2}-\ldots-\rho_{l} A_{S}+1>0$, that is, excluding zero $\rho_{l} A^{\prime}$ s I have to have $-\rho_{l} A_{1}^{+}-\ldots-\rho_{l} A_{m}^{+}+1>0$, and also take into account that $0<\frac{1}{1+\frac{1}{\delta_{1}^{2}}}<1$, which proves the sufficiency part of the second condition in Proposition 10. 


\section{A.6.6 Proof of Proposition 11}

For the case of $n=2$, the inequality in the alternative definition of $D$-stability looks as follows:

$$
\begin{aligned}
& \operatorname{det}\left[\frac{-\rho_{l} A_{1}}{1+\frac{i}{\delta_{1}}}+\ldots+\frac{-\rho_{l} A_{S}}{1+\frac{i}{\delta_{S}}}+I\right]=1+\operatorname{det} \frac{\left(-\rho_{l} A_{1}\right)}{1+\frac{i}{\delta_{1}}}+\ldots+\operatorname{det} \frac{\left(-\rho_{l} A_{S}\right)}{1+\frac{i}{\delta_{S}}}+\frac{M_{1}\left(-\rho_{l} A_{1}\right)}{1+\frac{i}{\delta_{1}}}+\ldots+\frac{M_{1}\left(-\rho_{l} A_{S}\right)}{1+\frac{i}{\delta_{S}}}+ \\
& +\operatorname{det} \operatorname{mix}\left(\frac{-\rho_{l} A_{1}}{1+\frac{i}{\delta_{1}}}, \frac{-\rho_{l} A_{2}}{1+\frac{i}{\delta_{2}}}\right)+\ldots+\operatorname{det} \operatorname{mix}\left(\frac{-\rho_{l} A_{S-1}}{1+\frac{i}{\delta_{S-1}}}, \frac{-\rho_{l} A_{S}}{1+\frac{i}{\delta_{S}}}\right)= \\
& =1+\left(\frac{1-\frac{i}{\delta_{1}}}{1+\frac{1}{\delta_{1}^{2}}}\right)^{2} \operatorname{det}\left(-\rho_{l} A_{1}\right)+\ldots+\left(\frac{1-\frac{i}{\delta_{S}}}{1+\frac{1}{\delta_{S}^{2}}}\right)^{2} \operatorname{det}\left(-\rho_{l} A_{S}\right)+ \\
& +\left(\frac{1-\frac{i}{\delta_{1}}}{1+\frac{1}{\delta_{1}^{2}}}\right) M_{1}\left(-\rho_{l} A_{1}\right)+\ldots+\left(\frac{1-\frac{i}{\delta_{S}}}{1+\frac{1}{\delta_{S}^{2}}}\right) M_{1}\left(-\rho_{l} A_{S}\right)+\ldots+ \\
& +\left(\frac{1-\frac{i}{\delta_{1}}}{1+\frac{1}{\delta_{1}^{2}}}\right)\left(\frac{1-\frac{i}{\delta_{2}}}{1+\frac{1}{\delta_{2}^{2}}}\right)\left[\operatorname{det} \operatorname{mix}\left(-\rho_{l} A_{1},-\rho_{l} A_{2}\right)+\operatorname{det} \operatorname{mix}\left(-\rho_{l} A_{2},-\rho_{l} A_{1}\right)\right]+\ldots+ \\
& +\left(\frac{1-\frac{i}{\delta_{S-1}}}{1+\frac{1}{\delta_{S-1}^{2}}}\right)\left(\frac{1-\frac{i}{\delta_{S}}}{1+\frac{1}{\delta_{S}^{2}}}\right)\left[\operatorname{det} \operatorname{mix}\left(-\rho_{l} A_{S-1},-\rho_{l} A_{S}\right)+\operatorname{det} \operatorname{mix}\left(-\rho_{l} A_{S},-\rho_{l} A_{S-1}\right)\right] \neq 0 \\
& \quad \text { for all } l=0,1, \ldots, k,\left(\rho_{0}=1\right) .
\end{aligned}
$$

Taking real and imaginary parts, one gets

$$
\begin{aligned}
& \operatorname{Redet}\left[\frac{-\rho_{l} A_{1}}{1+\frac{i}{\delta_{1}}}+\ldots+\frac{-\rho_{l} A_{S}}{1+\frac{i}{\delta_{S}}}+I\right]=1+\frac{1-\frac{1}{\delta_{1}^{2}}}{\left(1+\frac{1}{\delta_{1}^{2}}\right)^{2}} \operatorname{det}\left(-\rho_{l} A_{1}\right)+\ldots+ \\
& +\frac{1-\frac{1}{\delta_{S}^{2}}}{\left(1+\frac{1}{\delta_{S}^{2}}\right)^{2}} \operatorname{det}\left(-\rho_{l} A_{S}\right)+\frac{1}{1+\frac{1}{\delta_{1}^{2}}} M_{1}\left(-\rho_{l} A_{1}\right)+\ldots+\frac{1}{1+\frac{1}{\delta_{S}^{2}}} M_{1}\left(-\rho_{l} A_{S}\right)+\ldots+ \\
& +\frac{1-\frac{1}{\delta_{1} \delta_{2}}}{\left(1+\frac{1}{\delta_{1}^{2}}\right)\left(1+\frac{1}{\delta_{2}^{2}}\right)}\left[\operatorname{det} \operatorname{mix}\left(-\rho_{l} A_{1},-\rho_{l} A_{2}\right)+\operatorname{det} \operatorname{mix}\left(-\rho_{l} A_{2},-\rho_{l} A_{1}\right)\right]+\ldots+ \\
& +\frac{1-\frac{1}{\delta_{S-1} \delta_{S}}}{\left(1+\frac{1}{\delta_{S-1}^{2}}\right)\left(1+\frac{1}{\delta_{S}^{2}}\right)}\left[\operatorname{det} \operatorname{mix}\left(-\rho_{l} A_{S-1},-\rho_{l} A_{S}\right)+\operatorname{det} \operatorname{mix}\left(-\rho_{l} A_{S},-\rho_{l} A_{S-1}\right)\right] \\
& \operatorname{Im} \operatorname{det}\left[\frac{-\rho_{l} A_{1}}{1+\frac{i}{\delta_{1}}}+\ldots+\frac{-\rho_{l} A_{S}}{1+\frac{i}{\delta_{S}}}+I\right]=\frac{-\frac{2 i}{\delta_{1}}}{\left(1+\frac{1}{\delta_{1}^{2}}\right)^{2}} \operatorname{det}\left(-\rho_{l} A_{1}\right)+\ldots+
\end{aligned}
$$$$
+\frac{-\frac{2 i}{\delta_{S}}}{\left(1+\frac{1}{\delta_{S}^{2}}\right)^{2}} \operatorname{det}\left(-\rho_{l} A_{S}\right)+\frac{-\frac{i}{\delta_{1}}}{1+\frac{1}{\delta_{1}^{2}}} M_{1}\left(-\rho_{l} A_{1}\right)+\ldots+\frac{-\frac{i}{\delta_{S}}}{1+\frac{1}{\delta_{S}^{2}}} M_{1}\left(-\rho_{l} A_{S}\right)+\ldots+
$$$$
+\frac{-i\left(\frac{1}{\delta_{1}}+\frac{1}{\delta_{2}}\right)}{\left(1+\frac{1}{\delta_{1}^{2}}\right)\left(1+\frac{1}{\delta_{2}^{2}}\right)}\left[\operatorname{det} \operatorname{mix}\left(-\rho_{l} A_{1},-\rho_{l} A_{2}\right)+\operatorname{det} \operatorname{mix}\left(-\rho_{l} A_{2},-\rho_{l} A_{1}\right)\right]+\ldots+
$$$$
+\frac{-i\left(\frac{1}{\delta_{S-1}}+\frac{1}{\delta_{S}}\right)}{\left(1+\frac{1}{\delta_{S-1}^{2}}\right)\left(1+\frac{1}{\delta_{S}^{2}}\right)}\left[\operatorname{det} \operatorname{mix}\left(-\rho_{l} A_{S-1},-\rho_{l} A_{S}\right)+\operatorname{det} \operatorname{mix}\left(-\rho_{l} A_{S},-\rho_{l} A_{S-1}\right)\right]
$$

for all $l=0,1, \ldots, k\left(\rho_{0}=1\right)$ for all $l=0,1, \ldots, k\left(\rho_{0}=1\right)$. 
From the Im part of the determinant I see the "same sign" sufficient condition for this case:

$$
\begin{aligned}
& \quad \operatorname{det}\left(-\rho_{l} A_{i}\right) \geq 0,\left[\operatorname{det} \operatorname{mix}\left(-\rho_{l} A_{i},-\rho_{l} A_{j}\right)+\operatorname{det} \operatorname{mix}\left(-\rho_{l} A_{j},-\rho_{l} A_{i}\right)\right] \geq 0, i \neq j, \\
& M_{1}\left(-\rho_{l} A_{i}\right) \geq 0, \\
& \quad \text { or } \\
& \quad \operatorname{det}\left(-\rho_{l} A_{i}\right) \leq 0,\left[\operatorname{det} \operatorname{mix}\left(-\rho_{l} A_{i},-\rho_{l} A_{j}\right)+\operatorname{det} \operatorname{mix}\left(-\rho_{l} A_{j},-\rho_{l} A_{i}\right)\right] \leq 0, i \neq j, \\
& M_{1}\left(-\rho_{l} A_{i}\right) \leq 0 \text { for all } l=0,1, \ldots, k\left(\rho_{0}=1\right)
\end{aligned}
$$

If all inequalities above are equalities to zero, then the real part equals 1 , and the sufficient condition for $\delta$-stability holds true.

\section{A.6.7 Proof of Propositions 12 and 13}

I consider $\Gamma=D(-\Omega)$. A necessary and sufficient condition for stability of this matrix is that real parts of eigenvalues of $D(-\Omega)$ be greater than zero. And for the condition on eigenvalues to hold true it is necessary that all sums of principal minors of $D(-\Omega)$ grouped by the same size be greater than zero.

Indeed, the characteristic equation for eigenvalues of $\Gamma$ has the form

$$
\operatorname{det}(\Gamma+I \mu)=\operatorname{det} \Gamma+\mu M_{n-1}+\mu^{2} M_{n-2}+\ldots+\mu^{n-1} M_{1}+\mu^{n}=0, \text { where } \lambda=-\mu
$$

is the eigenvalue of $\Gamma$. and $M_{k}$ is the sum of all principal minors of $\Gamma$ of size $k$.

On the other hand, the same characteristic equation can be written in terms of the product decomposition of the polynomial:

$\mu^{n}=0$.

$$
\left(\mu+\lambda_{1}\right) \cdots\left(\mu+\lambda_{n}\right)=\underbrace{\lambda_{1} \ldots \lambda_{n}}_{>0}+\ldots+\mu^{n-2} \underbrace{\left(\lambda_{1} \lambda_{2}+\ldots+\lambda_{n-1} \lambda_{n}\right)}_{>0}+\mu^{n-1} \underbrace{\left(\lambda_{1}+\ldots+\lambda_{n}\right)}_{>0}+
$$

Thus, all $M_{k}>0$.

By writing this condition in terms of $D(-\Omega)$, one gets that in each size group the sum of minors is subdivided into groups of sums of minors that contain the same number of columns of each block of $(-\Omega)$, i.e. $A_{i}-I$. The coefficient before such particular sum has the form $\left(\delta_{h_{1}}\right)^{j_{1}}\left(\delta_{h_{2}}\right)^{j_{2}} \ldots\left(\delta_{h_{p}}\right)^{j_{p}}$. This coefficient uniquely specifies the sum of minors by the size, the number of columns from each block, and from which subeconomy it is formed, $\left(h_{1}, \ldots, h_{p}\right)$. The size of minors in such a group is equal to the total power of the coefficients, $j_{1}+\ldots+j_{p}$, and the subscripts of $\delta$ 's denote from which block of $(-\Omega)$ columns are taken, while the power of each 
$\delta$ indicates how many columns are taken from this particular block.

Let us fix one subeconomy (say, formed by blocks 1, 2, 3) and consider the limit of inequalities for the sum of minors, with $\delta$ 's for other blocks going to zero. Doing the same operation for all subeconomies, I will get condition $\left(^{*}\right)$. The statement in Proposition 13 is derived by setting all $\delta$ 's for all subeconomies in Condition $(*)$ equal to 1. 
Individual researchers, as well as the on-line and printed versions of the CERGE-EI Working Papers (including their dissemination) were supported from the following institutional grants:

- Center of Advanced Political Economy Research [Centrum pro pokročilá politickoekonomická studia], No. LC542, (2005-2009),

- Economic Aspects of EU and EMU Entry [Ekonomické aspekty vstupu do Evropské unie a Evropské měnové unie], No. AVOZ70850503, (2005-2010);

- Economic Impact of European Integration on the Czech Republic [Ekonomické dopady evropské integrace na ČR], No. MSM0021620846, (2005-2011);

Specific research support and/or other grants the researchers/publications benefited from are acknowledged at the beginning of the Paper.

(c) Dmitri Kolyuzhnov, 2008.

All rights reserved. No part of this publication may be reproduced, stored in a retrieval system or transmitted in any form or by any means, electronic, mechanical or photocopying, recording, or otherwise without the prior permission of the publisher.

Published by

Charles University in Prague, Center for Economic Research and Graduate Education (CERGE) and

Economics Institute ASCR, v. v. i. (EI)

CERGE-El, Politických vězňů 7, 11121 Prague 1, tel.: +420 224005 153, Czech Republic.

Printed by CERGE-EI, Prague

Subscription: CERGE-EI homepage: http://www.cerge-ei.cz

Editors: Directors of CERGE and EI

Managing editors: Deputy Directors for Research of CERGE and EI

ISSN 1211-3298

ISBN 978-80-7343-179-2 (Univerzita Karlova. Centrum pro ekonomický výzkum

a doktorské studium)

ISBN 978-80-7344-168-5 (Národohospodářský ústav AV ČR, v. v. i.) 
CERGE-EI

P.O.BOX 882

Politických vězňů 7

11121 Praha 1

Czech Republic http://www.cerge-ei.cz 